\title{
Optimization Method for Twin-Tunnel Complementary Ventilation Design and Its Energy Saving Effect
}

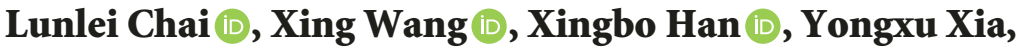 \\ Yongdong Wang $\mathbb{D}$, and Ping Lei $\mathbb{D}$
}

School of Highway, Chang'an University, Xian 710064, Shaanxi, China

Correspondence should be addressed to Lunlei Chai; 2015021002@chd.edu.cn

Received 18 December 2018; Revised 18 March 2019; Accepted 25 March 2019; Published 22 May 2019

Academic Editor: Eusebio Valero

Copyright (c) 2019 Lunlei Chai et al. This is an open access article distributed under the Creative Commons Attribution License, which permits unrestricted use, distribution, and reproduction in any medium, provided the original work is properly cited.

\begin{abstract}
Based on the compensation principle and optimization theory, an energy conservation optimization mode for twin-tunnels complementary ventilation design was proposed. And, compensation concept utilization in energy conservation of long tunnels ventilation was discussed. The energy consumption for long tunnels can be reduced significantly by remoulding longitudinal ventilation to complementary ventilation of single U-type mode or normal mode. The short-term and long-term ventilation systems of the Qingniling Tunnel, Dabieshan Tunnel, and Lianghekou Tunnel were redesigned using the optimization method, and the new scheme was compared to the original design in terms of ventilation effects, and energy consumption. In redesign, the energy consumption of short-term ventilation systems decreased $240 \mathrm{~kW}, 150 \mathrm{~kW}$, and $390 \mathrm{~kW}$, and energy efficiency increased by $40 \%$, $50 \%$, and $68.4 \%$, respectively. In the long term, the numbers of those were $1185 \mathrm{~kW}, 1185 \mathrm{~kW}$, and $540 \mathrm{~kW}$, and $42.5 \%, 58.09 \%$, and $45 \%$, while the pollutants concentration increased a little. The study can provide a reference for the energy efficient design of ventilation systems in long and extra-long highway tunnels.
\end{abstract}

\section{Introduction}

To provide adequate air quality during normal operational period, support self-evacuation and rescue efforts during emergency incidents, mechanical ventilation systems are often employed in vehicular tunnels [1-3]. Longitudinal, semi-transverse, and transverse ventilation systems are the traditional mechanical approaches employed in the design of vehicular tunnel ventilation systems $[4,5]$. Among these ventilation systems, longitudinal tunnel ventilation systems have been most widely adopted owing to the effective utilization of the piston wind [6-20]. And, ventilation shafts are often placed to divide tunnels into separate ventilation sections suitable for longitudinal tunnel ventilation in the extralong tunnels (longer than $3.00 \mathrm{~km}$ ), because the pollution concentration, increasing along the tunnel in the airflow direction, may exceed the admissible threshold. However, ventilation shafts bring about increase of ventilation system initial investment and operation energy consumption [21]. Twin-tunnel complementary ventilation system can solve this problem to some extent [22]. The system has two interchange channels between uphill tunnel and downhill tunnel, which allows the ample fresh air in the downhill tunnel to be used to complement the insufficient fresh air volume in the uphill tunnel. Compared with traditional ventilation systems, the twin-tunnel complementary ventilation system is a relatively innovative method, which has a number of advantages including low consumption of energy and construction, multiplexing, more reasonable distribution of pollutants concentration, and good visibility.

The concept of "twin-tunnel complementary" ventilation system was proposed by Bemer et al. for the first time in 1991 to solve the imbalance of ventilation requirement between uphill tunnel and downhill tunnel in some large single-slope twin tunnels, considering twin tunnels as a single unit rather than as two separated tunnels [23]. The concept came into practice for the first time in Ping-Lin tunnel in Taiwan, and the investment and operation cost of the tunnel are reduced largely [7]. Then, Zhang et al. applied such a ventilation scheme in the ancillary tunnel works of the Jinping Hydropower Station. Relevant calculation methods were also proposed through theoretical analysis, and the 
scheme was named the air interchange system for road tunnel longitudinal ventilation owing to its airflow exchange characteristics between the double-line tunnels [24]. Wang et al. further developed the ventilation scheme and applied it in the Dabieshan Highway Tunnel [25-27], Qingniling Highway Tunnel, Lianghekou Tunnel, and Jiuling Tunnel, and obtained economic and ecological benefits. Ren et al. investigated the effectiveness of twin-tunnel complementary ventilation by the numerical simulation. The results showed that the distance from air interchange channels to the uphill-tunnel inlet is the most important factor involved in influencing the ventilation efficiency rather than the flow volume of air interchange channel and the jet fan thrust in tunnel on the ventilation efficiency [22].

In the complementary ventilation design of the above projects, the sum of the required air volume for dilution of key pollutants in the double-line tunnels is taken as the total design air volume, an equal design air volume for the uphill and downhill tunnels is taken as the most costoptimal air distribution scheme, and the interchange air volume is defined to make the concentration of key pollutants at the exit of the downhill tunnel equal to that at the exit of the uphill tunnel [26]. Although Chai et al. proposed an improved method, which considered differences in key pollutants in the uphill and downhill tunnels and a larger design of air volume is allocated to the uphill tunnel to reduce the energy consumption of the interchange channel and total energy consumption [28], the key factors are determined by repeatedly calculations, which are often complex with heavy computing burden, and easily to be error; meanwhile, the result may not the best for energy-saving. Therefore, a simplified design method is needed.

Additionally, in the above researches, the twin-tunnel complementary ventilation systems were all investigated under the employment in the extra-long double-line tunnels to instead the longitudinal ventilation with a ventilation shaft or inclined shaft. The energy-saving of remoulding longitudinal ventilation into complementary ventilation was ignored. In this paper, the energy-saving optimization model for twintunnel complementary ventilation system was proposed, and the twin-tunnel complementary ventilation system utilization in energy-saving of remoulding longitudinal ventilation was discussed. The results can help engineers better understand the twin-tunnel complementary ventilation system, to design an effective ventilation system for double-line tunnel.

\section{Energy-Saving Optimization Model for Complementary Ventilation}

In the complementary ventilation design of the above projects, the sum of the required air volume for dilution of key pollutants in the double-line tunnels is taken as the total design air volume, an equal design air volume for the uphill and downhill tunnels is taken as the most cost-optimal air distribution scheme, and the interchange air volume is defined to make the concentration of key pollutants at the exit of the downhill tunnel equal to that at the exit of the uphill tunnel [26]. Although Chai et al.

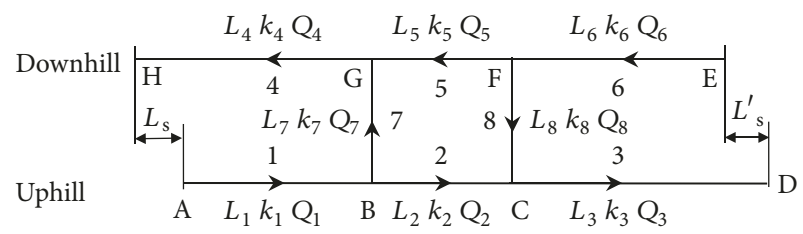

FIgURE 1: A complementary ventilation network.

proposed an improved method, which considered differences in key pollutants in the uphill and downhill tunnels and a larger design of air volume is allocated to the uphill tunnel to reduce the energy consumption of the interchange channel and total energy consumption, and the key factors are determined by repeatedly calculations. The calculations are often complex with heavy computing burden, and easily to be error; meanwhile, the result may not the best for energysaving. Therefore, a simplified design method is needed. The energy-saving optimization model is proposed to solve this problem.

2.1. Energy Consumption Function. In complementary ventilation systems, the uphill and downhill tunnels were divided into 6 sections by the two interchange channels, as shown in Figure 1. The high concentrated polluted air in branch 1 passes through branch 7 ( $1^{\#}$ interchange channel) into branch 4 , while the low concentrated polluted air in branch 6 passes through branch 8 ( $2^{\#}$ interchange channel) into branch 3 . Owing to the concentration difference between the exchange flow, the pollutants exceeding the dilution capacity of design air volume in uphill tunnel are transferred to the downhill tunnel and diluted by the increased design air volume.

In airway $j$, the pressure losses, $P_{\mathrm{Rj}}(\mathrm{Pa})$, can be related to the square of the volume flow through the airway $Q_{j}\left(\mathrm{~m}^{3} / \mathrm{s}\right)$, with a constant of proportionality being the resistance, $\mathrm{R}$ $\left(\mathrm{Ns}^{2} / \mathrm{m}^{8}\right.$ or $\left.\mathrm{kg} / \mathrm{m}^{7}\right)$ of the airway by the Atkinson's equation [29]:

$$
P_{R j}=R_{j} Q_{j}^{2}
$$

where airway resistance $\left(R_{\mathrm{j}}\right)$ consists of resistance caused by friction between airflow and tunnel wall, roof, and floor (frictional resistance) plus resistance caused by bends, changes in tunnel cross sectional dimension, and branches (shock loss). It is calculated using this equation:

$$
\begin{aligned}
R_{j} & =\left(\frac{\lambda_{j} L_{j}}{D_{j}}+\xi_{j}\right) \cdot \frac{\rho}{2} \cdot \frac{1}{A_{j}{ }^{2}} \\
& =\left(\lambda_{j} L_{j} \frac{U_{j}}{4 A_{j}}+\xi_{j}\right) \cdot \frac{\rho}{2} \cdot \frac{1}{A_{j}{ }^{2}}
\end{aligned}
$$

where $\lambda_{\mathrm{j}}$ is the frictional coefficient (dimensionless), $\xi_{j}$ is the shock loss factor (dimensionless), $L_{j}$ is length of the airway (dimensionless), $D_{j}=4 A_{\mathrm{j}} / U_{\mathrm{j}}$ is hydraulic diameter of the airway $(\mathrm{m}), U_{\mathrm{j}}$ is the airway cross sectional perimeter $(\mathrm{m}), A_{j}$ is airway cross section area $\left(\mathrm{m}^{2}\right)$, and $\rho$ is density of airflow inside the airway $(\mathrm{kg} / \mathrm{m} 3)$. 
According to the law of conservation of energy, and the network of complementary system as shown in Figure 1, the required fans thrust $P_{\mathrm{Fj}}$ can be calculated as

$$
\begin{aligned}
P_{\mathrm{F} 1} & +P_{\mathrm{T} 1}-P_{\mathrm{N} 1}+P_{\mathrm{F} 2}+P_{\mathrm{T} 2}-P_{\mathrm{N} 2}+P_{\mathrm{F} 3}+P_{\mathrm{T} 3}-P_{\mathrm{N} 3} \\
& =P_{\mathrm{R} 1}+P_{\mathrm{R} 2}+P_{\mathrm{R} 3} \\
P_{\mathrm{F} 1} & +P_{\mathrm{T} 1}-P_{\mathrm{N} 1}+P_{\mathrm{F} 7}+P_{\mathrm{T} 7}-P_{\mathrm{N} 7}+P_{\mathrm{F} 4}+P_{\mathrm{T} 4}-P_{\mathrm{N} 4} \\
& =P_{\mathrm{R} 1}+P_{\mathrm{R} 7}+P_{\mathrm{R} 4} \\
P_{\mathrm{F} 6} & +P_{\mathrm{T} 6}-P_{\mathrm{N} 6}+P_{\mathrm{F} 5}+P_{\mathrm{T} 5}-P_{\mathrm{N} 5}+P_{\mathrm{F} 4}+P_{\mathrm{T} 4}-P_{\mathrm{N} 4} \\
= & P_{\mathrm{R} 6}+P_{\mathrm{R} 5}+P_{\mathrm{R} 4} \\
P_{\mathrm{F} 6} & +P_{\mathrm{T} 6}-P_{\mathrm{N} 6}+P_{\mathrm{F} 8}+P_{\mathrm{T} 8}-P_{\mathrm{N} 8}+P_{\mathrm{F} 3}+P_{\mathrm{T} 3}-P_{\mathrm{N} 3} \\
= & P_{\mathrm{R} 6}+P_{\mathrm{R} 8}+P_{\mathrm{R} 3} \\
P_{\mathrm{F} 7} & +P_{\mathrm{T} 7}-P_{\mathrm{N} 7}-P_{\mathrm{R} 7}+P_{\mathrm{F} 8}+P_{\mathrm{T} 8}-P_{\mathrm{N} 8}-P_{\mathrm{R} 8} \\
= & P_{\mathrm{F} 5}+P_{\mathrm{T} 5}-P_{\mathrm{N} 5}-P_{\mathrm{R} 5}+P_{\mathrm{F} 2}+P_{\mathrm{T} 2}-P_{\mathrm{N} 2}-P_{\mathrm{R} 2}
\end{aligned}
$$

where the traffic force $P_{\mathrm{Tj}}(\mathrm{Pa})$ and nature wind pressure $P_{\mathrm{Nj}}$ (Pa) can be obtained from the geometrical cross-section of a car $A_{m}\left(\mathrm{~m}^{2}\right)$, the traffic flow per hour $n(\mathrm{veh} / \mathrm{h})$, vehicle velocity $v_{T}(\mathrm{~m} / \mathrm{s})$, the length of uphill and downhill tunnel $L_{\mathrm{U}}(\mathrm{m})$ and $L_{\mathrm{D}}(\mathrm{m})$, and the nature wind pressure of uphill and downhill tunnel $P_{\mathrm{NU}}(\mathrm{Pa})$ and $P_{\mathrm{ND}}(\mathrm{Pa})$. The calculation methods are

$$
\begin{aligned}
& P_{\mathrm{Tj}}=\frac{A_{m}}{A_{j}} \frac{\rho}{2} \frac{n L_{j}}{3600 v_{T}}\left(v_{T}-\frac{Q_{j}}{A_{j}}\right)\left|v_{T}-\frac{Q_{j}}{A_{j}}\right| \\
& P_{\mathrm{Nj}}= \begin{cases}\frac{L_{\mathrm{j}}}{L_{\mathrm{U}}} P_{\mathrm{NU}} & (\mathrm{j}=1,2,3) \\
\frac{L_{\mathrm{j}}}{L_{\mathrm{D}}} P_{\mathrm{ND}} & (\mathrm{j}=4,5,6)\end{cases}
\end{aligned}
$$

Then, the output power of fans $N_{j}$ can be calculated as

$$
\begin{aligned}
N_{\mathrm{j}} & =P_{\mathrm{Fj}} Q_{j}=\left(P_{\mathrm{Rj}}+P_{\mathrm{Tj}}-P_{\mathrm{Nj}}\right) Q_{j} \\
& =k_{j} Q_{j}{ }^{3}+\left(P_{\mathrm{Tj}}-P_{\mathrm{Nj}}\right) Q_{j}
\end{aligned}
$$

Considering the fan motor efficiency $\eta$, the energy consumption of section branch $j$ can be calculated as

$$
N_{j}^{\prime}=\frac{N_{j}}{\eta}
$$

The total energy consumption of the network can be calculated as

$$
N=\sum N^{\prime}{ }_{j}=\frac{\sum N_{j}}{\eta}
$$

2.2. Decision Variables and Constraints. As the above analysis, the energy consumption of network is influenced by the length and the air volume of each branch. And the variables are subject to the follow constraints:
(1) Design air volumes. As the interchange channels connect the single tunnels as a combined system, the design air volumes of complementary ventilation system should meet:

$$
Q_{1}+Q_{6} \geq \max \left(Q_{D i}+Q_{U i}\right)
$$

where $Q_{1}$, and $Q_{6}$ are the design air volumes of the uphill and downhill tunnels for complementary ventilation, respectively; $Q_{\mathrm{U} i}$ and $Q_{\mathrm{D} i}(i=1,2,3$, or 4$)$ are the required air volumes for diluting $\mathrm{CO}$ (Carbon monoxide) and smoke (VI) and the minimum air exchange rate and smoke extraction during a fire in the double-line tunnels, respectively, which can be calculated by Eq. (10).

$$
\begin{aligned}
Q_{\mathrm{D} 1}, Q_{\mathrm{U} 1}= & \frac{1}{3.6} q_{\mathrm{CO}} \cdot f_{\mathrm{a}(\mathrm{CO})} \cdot f_{\mathrm{d}} \cdot f_{\mathrm{h}(\mathrm{CO})} \cdot f_{\mathrm{iv}(\mathrm{CO})} \cdot f_{\mathrm{t}} \\
& \cdot L \cdot \sum_{m=1}^{n} \frac{\left(N_{\mathrm{m}} \cdot f_{\mathrm{m}(\mathrm{CO})}\right)}{\delta_{\mathrm{CO}}} \\
Q_{\mathrm{D} 2}, Q_{\mathrm{U} 2}= & \frac{1}{3.6 \times 10^{6}} q_{\mathrm{VI}} \cdot f_{\mathrm{a}(\mathrm{VI})} \cdot f_{\mathrm{d}} \cdot f_{\mathrm{h}(\mathrm{VI})} \cdot f_{\mathrm{iv}(\mathrm{VI})} \\
& \cdot f_{\mathrm{t}} \cdot L \cdot \sum_{m=1}^{n_{\mathrm{D}}} \frac{\left(N_{\mathrm{Dm}} \cdot f_{\mathrm{m}(\mathrm{VI})}\right)}{\delta_{\mathrm{VI}}} \\
Q_{\mathrm{D} 3}, Q_{\mathrm{U} 3}= & \max \left(\frac{A_{\mathrm{r}} \cdot L \cdot n_{\mathrm{s}}}{3600}, A_{\mathrm{r}} \cdot v_{\mathrm{ac}}\right) \\
Q_{\mathrm{D} 4}, Q_{\mathrm{U} 4}= & 3 \cdot A_{\mathrm{r}}
\end{aligned}
$$

where $q_{\mathrm{CO}}, q_{\mathrm{VI}}$ base emission of $\mathrm{CO}\left[\mathrm{m}^{3} /(\mathrm{veh} \cdot \mathrm{km})\right]$, smoke $\left[\mathrm{m}^{2} /(\mathrm{veh} \cdot \mathrm{km})\right]$ for base year $2000 ; f_{\mathrm{a}(\mathrm{CO})}, f_{\mathrm{a}(\mathrm{VI})}$ influence factors for road on $\mathrm{CO}$, smoke emission $(-) ; f_{\mathrm{d}}$ influence factors for traffic density $(-) ; f_{\mathrm{h}(\mathrm{CO})}, f_{\mathrm{h}(\mathrm{VI})}$ influence factors for altitude of tunnels on CO, smoke emission $(-) ; f_{\mathrm{iv}(\mathrm{CO})}$, $f_{\mathrm{iv}(\mathrm{VI})}$ influence factors depended on average speed and road gradient $(-) ; f_{\mathrm{t}}$ influence factors for years differing from the base year (-); $L$ length of uphill or downhill tunnel (m); n, $n_{D}$ the number of vehicle type and diesel vehicle type; $N_{\mathrm{m}}$, $N_{\mathrm{Dm}}$ traffic volume for each vehicle type; $f_{\mathrm{m}(\mathrm{CO})}, f_{\mathrm{m}(\mathrm{VI})}$ factor depended on vehicle type; $\delta_{\mathrm{CO}}, \delta_{\mathrm{VI}}$ admissible values for $\mathrm{CO}$ $(\mathrm{ppm})$, smoke $\left(\mathrm{m}^{-1}\right) . A_{\mathrm{r}}$ cross-section of uphill or downhill tunnel $\left(\mathrm{m}^{2}\right), n_{\mathrm{s}}$ the minimum frequency of air exchange; $v_{\mathrm{ac}}$ the minimum air velocity in longitudinal ventilation $(\mathrm{m} / \mathrm{s})$.

As Eq. (10) shows, the required air volumes for minimum air exchange and smoke extraction during a fire are determined by the length and cross-section of tunnels, so the required air volumes for the uphill and downhill tunnel are similar, while the required air volumes for diluting $\mathrm{CO}$ and smoke are influenced by tunnels altitude, and road gradient. Although altitudes of uphill and downhill tunnel are similar and gradient changes do not greatly affect the vehicle's $\mathrm{CO}$ emissions, the high smoke emissions of diesel engines create different ventilation flow requirements. As Table 1 shows, under $80 \mathrm{~km} / \mathrm{h}$, the value of $f_{\mathrm{iv}(\mathrm{CO})}$ is 1.0 for a $-3 \%$ gradient and 1.2 for one of $3 \%$, the increasing ratio is only $20 \%$, but the value of $f_{\mathrm{iv}(\mathrm{VI})}$ increases from 0.4 to 4.4 , and a 10 times increase is gotten. This means that the required air volume for 
the uphill tunnel must be far higher than that for the downhill tunnel.

(2) Continuity of airflow. The ventilation system works in incompressible condition, so the air volumes should meet:

$$
\begin{aligned}
& Q_{3}=Q_{2}+Q_{8} \\
& Q_{1}=Q_{2}+Q_{7} \\
& Q_{4}=Q_{5}+Q_{7} \\
& Q_{6}=Q_{5}+Q_{8}
\end{aligned}
$$

And if $Q_{7}=0, Q_{8} \neq 0$, the ventilation is the single U-type mode; if $Q_{7}=Q_{8}=0$, the ventilation is normal longitudinal ventilation. In this situation, the ventilation system for uphill or downhill tunnel is independent, and the pollution by air exchange between the uphill tunnel and downhill tunnel is increasing. The pollutant concentration gets the maximum value at the outlet of uphill and downhill tunnels. So the design air volumes $Q_{1}$ and $Q_{6}$ should meet: $Q_{1} \geq \max \left(Q_{U i}\right)$, $Q_{6} \geq \max \left(Q_{D i}\right)$ to ensure the pollutants concentration under the admissible values.

(3) Air velocity limit. The air velocity in tunnel should not exceed the maximum allowable air velocity $v_{\max }$, and the minimum air velocity for air exchange is $1.5 \mathrm{~m} / \mathrm{s}$ [30]. So, the air volumes of branch $j$ should meet:

$$
\begin{aligned}
& Q_{j} \geq 1.5 \cdot A_{j} \\
& Q_{j} \leq v_{\max } \cdot A_{j}
\end{aligned}
$$

$$
(j=1,2, \cdots, 6)
$$

(4) Admissible concentration. The pollutants concentration should not exceed the admissible values. In the ventilation network, there are four key points, the outlet of branch 2,3,4,5, where the concentration of pollutions is greater than the upstream sections. So, the constraints of admissible concentration can be taken as

$$
\begin{array}{r}
\frac{q_{U} L_{1}}{L_{U} Q_{1}}+\frac{q_{U} L_{2}}{L_{U} Q_{2}} \leq \delta \\
\frac{\left(q_{U}-q_{U} L_{1} Q_{7} / L_{U} Q_{1}+q_{D} L_{6} Q_{8} / L_{D} Q_{6}\right)}{Q_{3}} \leq \delta \\
\frac{q_{D} L_{6}}{L_{D} Q_{6}}+\frac{q_{D} L_{5}}{L_{D} Q_{5}} \leq \delta \\
\frac{\left(q_{D}+q_{U} L_{1} Q_{7} / L_{U} Q_{1}-q_{D} L_{6} Q_{8} / L_{D} Q_{6}\right)}{Q_{4}} \leq \delta
\end{array}
$$

As $q_{\mathrm{U}} / Q_{\mathrm{U}}=q_{\mathrm{D}} / Q_{\mathrm{D}}=\delta$, the following is obtained:

$$
\begin{array}{r}
\frac{Q_{U} L_{1}}{L_{U} Q_{1}}+\frac{Q_{U} L_{2}}{L_{U} Q_{2}} \leq 1 \\
\frac{\left(Q_{U}-Q_{U} L_{1} Q_{7} / L_{U} Q_{1}+Q_{D} L_{6} Q_{8} / L_{D} Q_{6}\right)}{Q_{3}} \leq 1 \\
\frac{Q_{D} L_{6}}{L_{D} Q_{6}}+\frac{Q_{D} L_{5}}{L_{D} Q_{5}} \leq 1 \\
\frac{\left(Q_{D}+Q_{U} L_{1} Q_{7} / L_{U} Q_{1}-Q_{D} L_{6} Q_{8} / L_{D} Q_{6}\right)}{Q_{4}} \leq 1
\end{array}
$$

where the $q_{\mathrm{U}}, q_{\mathrm{D}}, Q_{\mathrm{U}}$, and $Q_{\mathrm{D}}$ are the vehicular emission pollutants ( $\mathrm{CO}$ and smoke) and the required air volume for diluting those in uphill and downhill tunnels, respectively.

(5) Geometric constraints. As branch 1, branch 2, and branch 3 are in the uphill tunnel and branch 4, branch 5, and branch 6 are in the downhill tunnel, the lengths of branches should meet:

$$
\begin{aligned}
& L_{\mathrm{U}}=L_{1}+L_{2}+L_{3} \\
& L_{\mathrm{D}}=L_{4}+L_{5}+L_{6}
\end{aligned}
$$

As the Figure 1 shown, the channels are often parallel and perpendicular to the tunnels, so the lengths of branches 2 and 5 should meet:

$$
L_{2}=L_{5}
$$

And there is often a distance $L_{\mathrm{s}}$ between the inlet of uphill tunnel and the outlet of downhill tunnel, so the lengths of branches 1 and 4 should meet:

$$
L_{4}=L_{1}+L_{\mathrm{s}}
$$

where the sign of $L_{\mathrm{s}}$ is determined by the relative location of uphill inlet and downhill outlet.

In complementary ventilation system, air flow near interchange channels should be as Figure 2(b). But if the lengths of branches 2 and 5 are too short to eliminate the backflow from one air interchange channel outlet to the other's inlet, the air would flow as Figure 2(a). [22, 28] So $L_{2}$ and $L_{5}$ should meet:

$$
L_{2}=L_{5} \geq l_{\min }
$$

(6) Mathematical constraints. All the variables should be nonnegative. Additionally, in order to reduce the solve time of this model and provide the convenience for construction, $L_{1}$ and $L_{2}$ can be taken as the multiple of $I N T_{1}$ and $I N T_{2}$, as Eq. (19), where $I N T_{1}, I N T_{1}$ can be set as $50 \mathrm{~m}, 20 \mathrm{~m}, 10 \mathrm{~m} 5 \mathrm{~m}$, $1 \mathrm{~m}$ et $\mathrm{al}$, and determined by the design precision.x

$$
\begin{gathered}
\frac{L_{1}}{I N T_{1}}, \frac{L_{2}}{I N T_{2}}=\text { integer } \\
L_{j}, Q_{j} \geq 0
\end{gathered}
$$

2.3. Optimization Model. Based on the above analysis, the energy saving optimization model is built up and may be written as 


$$
\begin{aligned}
\min & N=\sum N^{\prime}{ }_{j}=\frac{\sum N_{j}}{\eta} \\
\text { Subject to (s.t.) } & Q_{1}+Q_{6} \geq \max \left(Q_{D i}+Q_{U i}\right) \\
& Q_{3}=Q_{2}+Q_{8} \\
& Q_{1}=Q_{2}+Q_{7} \\
& Q_{4}=Q_{5}+Q_{7} \\
& Q_{6}=Q_{5}+Q_{8} \\
& 1.5 \cdot A_{j} \leq Q_{j} \leq v_{\max } \cdot A_{j} \\
& L_{U}=L_{1}+L_{2}+L_{3} \\
& L_{D}=L_{4}+L_{5}+L_{6} \\
& L_{4}=L_{1}+L_{s} \\
& L_{2}=L_{5} \geq l_{\min } \\
& \frac{Q_{U} L_{1}}{L_{U} Q_{1}}+\frac{Q_{U} L_{2}}{L_{U} Q_{2}} \leq 1 \\
& \frac{\left(Q_{U}-Q_{U} L_{1} Q_{7} / L_{U} Q_{1}+Q_{D} L_{6} Q_{8} / L_{D} Q_{6}\right)}{Q_{3}} \leq 1 \\
& \frac{Q_{D} L_{6}}{L_{D} Q_{6}}+\frac{Q_{D} L_{5}}{L_{D} Q_{5}} \leq 1 \\
& \frac{\left(Q_{D}+Q_{U} L_{1} Q_{7} / L_{U} Q_{1}-Q_{D} L_{6} Q_{8} / L_{D} Q_{6}\right)}{Q_{4}} \leq 1 \\
& \frac{L_{1}}{I N T_{1}}, \frac{L_{2}}{I N T_{2}}=\text { integer } \\
& L_{j}, Q_{j} \geq 0
\end{aligned}
$$

\section{Utilization in Energy Conservation of Long Tunnels}

The flow of fresh air needed to maintain the air quality in a road tunnel is determined by the tunnel's length and the amount of pollutants emitted by the vehicles travelling through it. This is a function of the amount of traffic, its speed, and the gradient and altitude of the road $[23,30]$. Especially, gradient often leads to the fact that the design ventilation flow for the uphill tunnel must be far higher than that for the downhill tunnel. Table 2 shows some long and extra-long twin tunnels' design ventilation flow for the uphill and downhill tunnels. The design ventilation flow ratio of uphill and downhill tunnel can reach 2.59. As the maximum allowable flow velocity limit, the uphill tunnels are usually divided into separate ventilation sections and exchange polluted air with fresh air via a ventilation shaft at the end of each section. And the complementary ventilation system is employed in some extra-long tunnels whose design ventilation flow of the uphill tunnel exceeds the maximum allowable flow velocity limit, but the sum of the uphill and downhill tunnels is lower than the double of the limits. Great economic and ecological benefits have been obtained for its low energy consumption by decreasing the flow velocity in the uphill tunnel.
However, this advantage has not been developed for the long-tunnel energy saving, in which longitudinal ventilation is often applied. Even though the energy consumption of single long tunnel often is lower than that of extra-long tunnel for its lower required air volume and resistance, but its number is huge, there are 3841 long tunnels (length 1000 $3000 \mathrm{~m}$ ), but only 902 extra-long tunnels (length $\geq 3000 \mathrm{~m}$ ) in Chinese highway end of 2017. The accumulative effect of energy saving is considerable.

The energy consumption can be reduced significantly by remoulding the longitudinal ventilation to the complementary ventilation, either the single U-type ventilation mode or the normal mode.

In the single U-type mode, the fresh air volume that gets from the uphill inlet is insufficient and is complemented with the fresh air getting from the downhill inlet via the air interchange channel near the uphill outlet and the downhill outlet so that the flow velocity can be reduced in most sections to reduce the frictional resistance and the required fans thrust, as shown in Figure 3(a).

In normal complementary mode, the design air volume of the uphill tunnel is decreased, while that of the downhill tunnel is increased, but the total required fans thrust is decreased because the required fans thrust of single tunnel is directly proportional to the cube of the air volume. 
TABLE 1: Values of $f_{\mathrm{iv}(\mathrm{CO})}, f_{\mathrm{iv}(\mathrm{VI})}$ under different gradient at $80 \mathrm{~km} / \mathrm{h}$.

\begin{tabular}{lccccccccc}
\hline Gradients (\%) & -4 & -3 & -2 & -1 & 0 & 1 & 2 & 3 & 4 \\
\hline$f_{\text {iv }(\mathrm{CO})}$ & 1.0 & 1.0 & 1.0 & 1.0 & 1.0 & 1.0 & 1.2 & 1.2 & 1.2 \\
$f_{\text {iv }(\mathrm{VI})}$ & 0.3 & 0.4 & 0.55 & 0.8 & 1.3 & 2.6 & 3.7 & 4.4 & - \\
\hline
\end{tabular}

TABLE 2: Design ventilation flow of some long and extra-long twin tunnels.

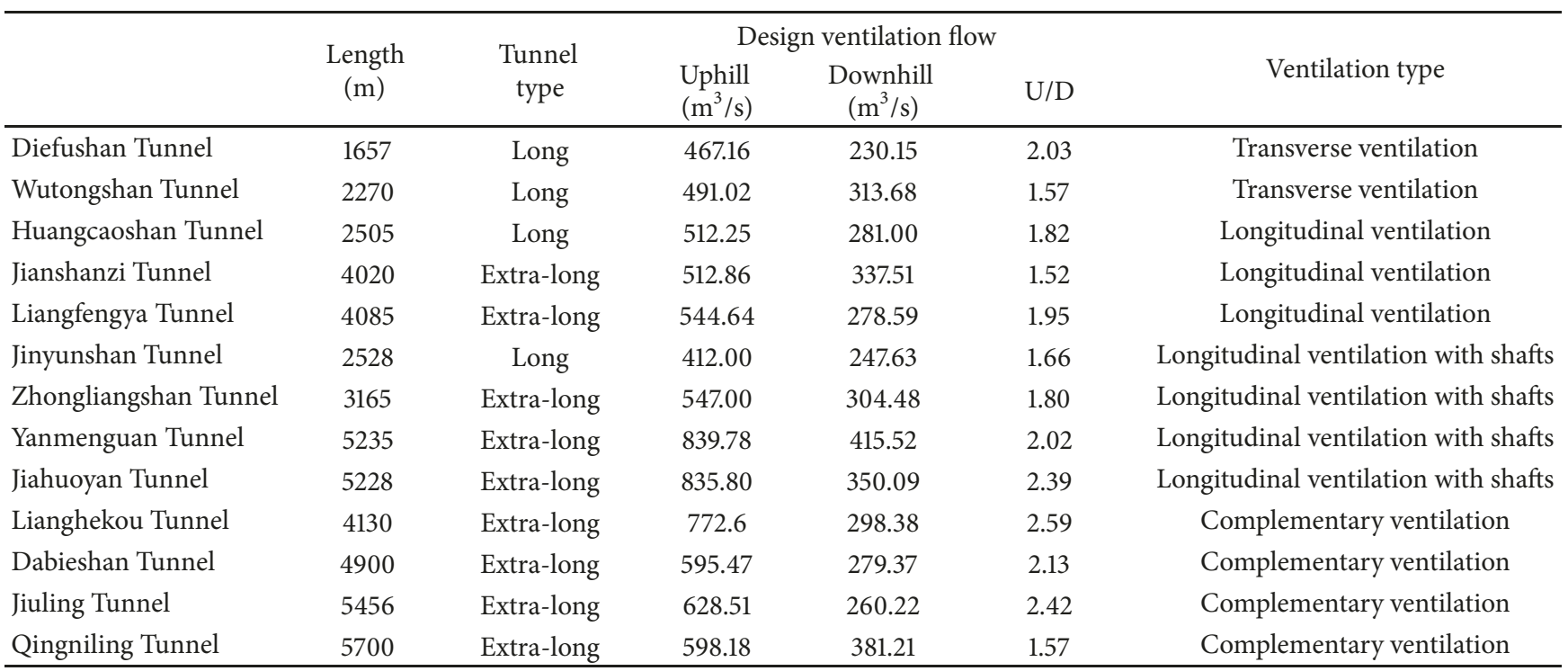

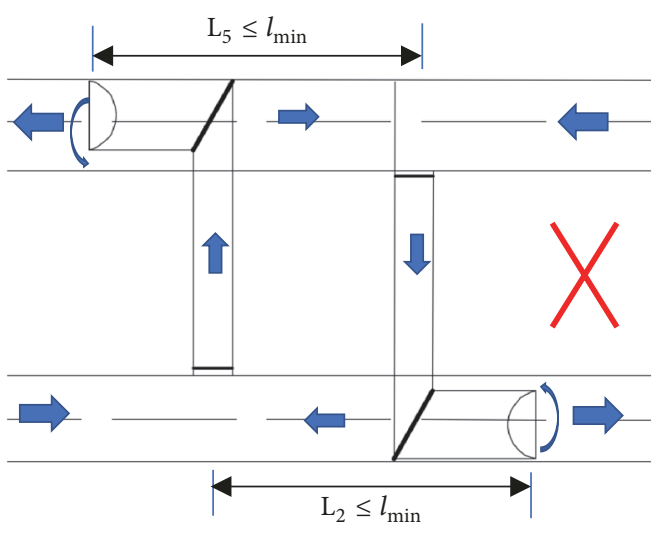

(a) Backflow near the channels

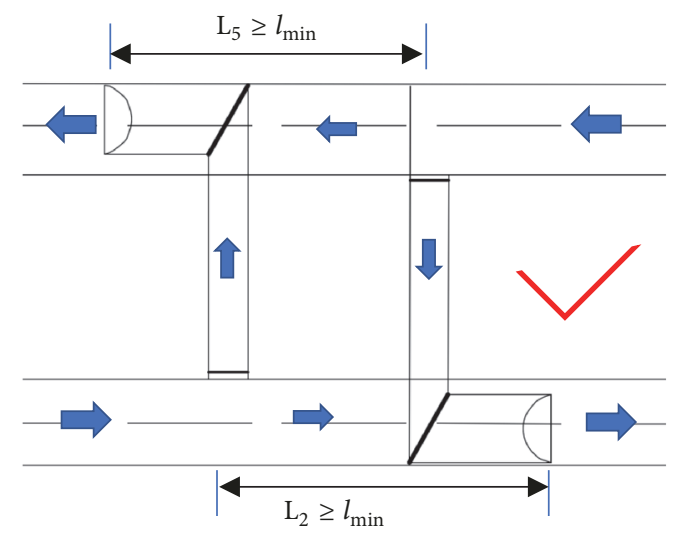

(b) Normal air flow

Figure 2: Air flow near the interchange channels.

Meanwhile, if the design air volume of the downhill tunnel is determined by the minimum air exchange, the total design air volume can be reduced so that the flow velocity can be reduced in both uphill and downhill tunnels, as shown in Figure 3(b). The frictional resistance and the required fans thrust can be reduced further.

Because the pollutants transfer is not necessary, the distance between the two air interchange channels can be extended. When the first channel is located at the upstream of uphill and the second channel is located at downstream of uphill, the pressure difference between the channel inlet and outlet can induce the flow into the channel, and the axis fans installed in channels are not necessary. And crosspassageways for vehicle and people passing can be used as air interchange channels to reduce the construction cost.

\section{Case Study}

4.1. Project Overview. The Qingniling Tunnel is one of the main highway tunnels linking Shiyan with Tianshui. It is designed as a separated four-lane double-line tunnel, the 


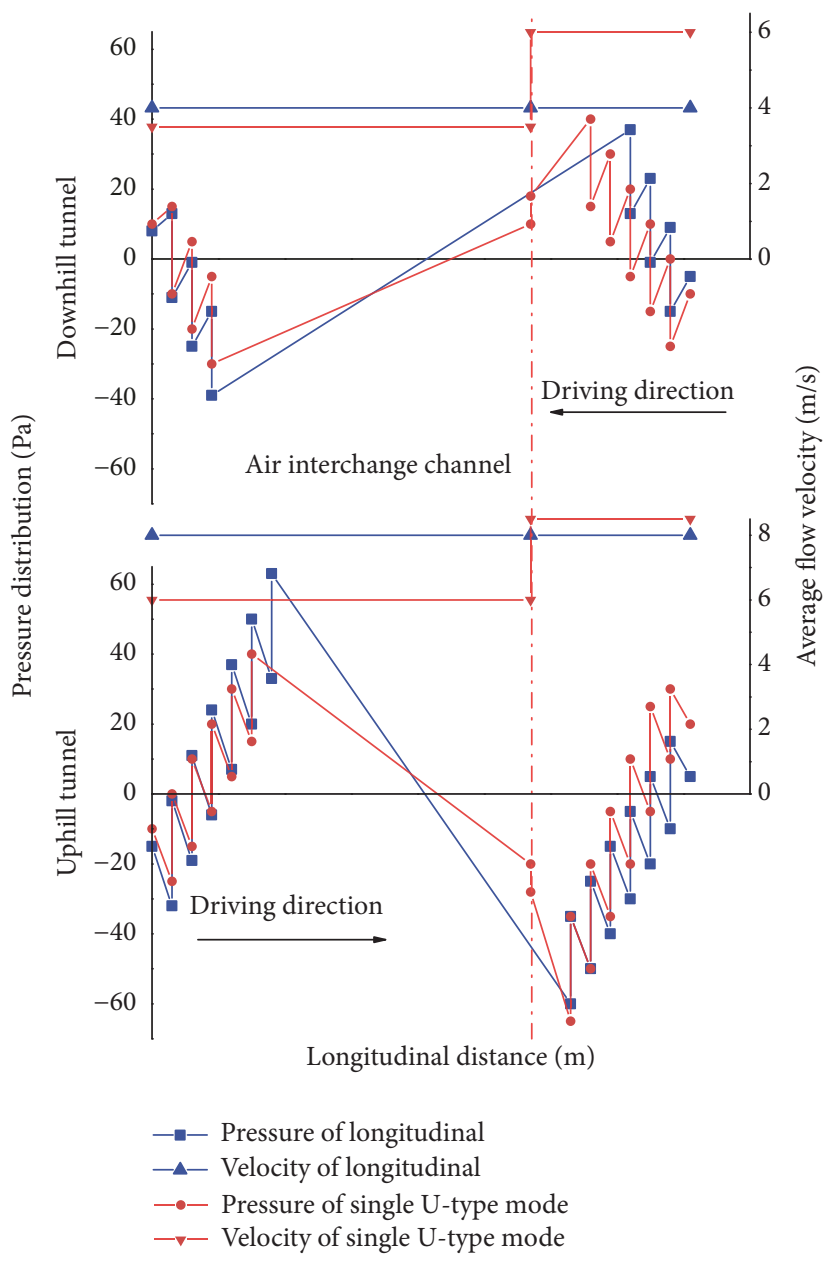

(a) Single U-type complementary ventilation mode

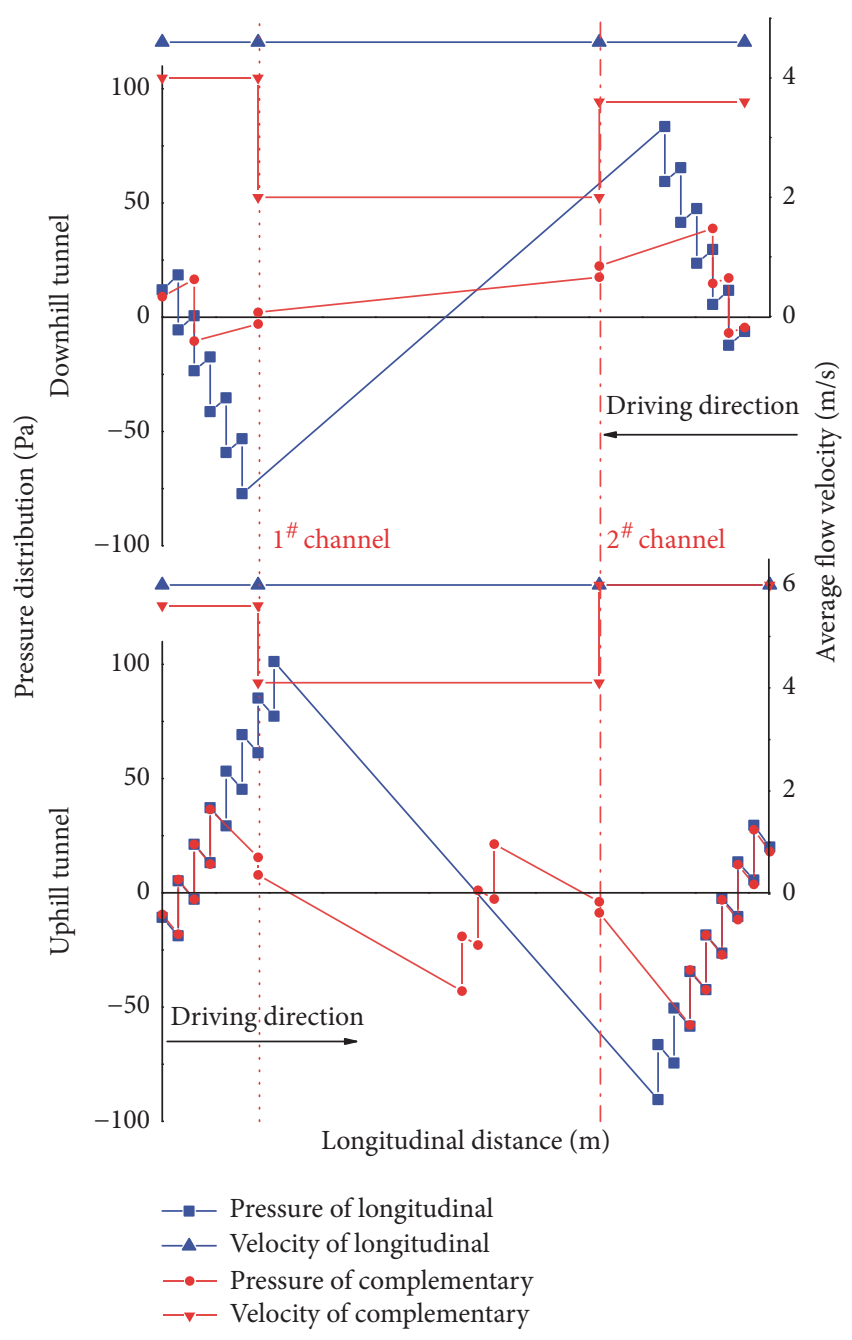

(b) Normal complementary ventilation mode

FIGURE 3: Pressure and velocity profile for complementary remoulding of longitudinal ventilation.

downhill tunnel is $5464 \mathrm{~m}$ with slope of $-2 \%$, and the uphill tunnel is $5700 \mathrm{~m}$, which consists of $5060 \mathrm{~m}$ with slope of $1.99 \%$ and $640 \mathrm{~m}$ with slope of $1.385 \%$, as shown in Figure 4. The average designed elevations of the uphill and downhill tunnel are 877.4 and $876.6 \mathrm{~m}$, respectively. In the twin-tunnel with unidirectional traffic, the design driving speed is $80 \mathrm{~km} / \mathrm{h}$, and the cross-sectional area is $62.79 \mathrm{~m}^{2}$. The maximum ventilation airflow velocity for the two tunnels is defined as $8 \mathrm{~m} / \mathrm{s}$. The predicted peak traffic is 1082 vehicles/h in 2025 and 2032 vehicles/h in 2033. The nature wind pressures of the uphill and downhill tunnel are $78.68 \mathrm{~Pa}$ and $75.22 \mathrm{~Pa}$, respectively. The required air volumes under different conditions in the left (downhill) and right tunnels (uphill) are summarised in Table 3 . In original design, the longitudinal ventilation is employed for the short term (2025), the complementary ventilation is employed for the long term (2033), and the ventilation system layout is shown in Figure 5 [26]. But the required air flow ratio of the uphill and downhill tunnel is 1.32 when the longitudinal ventilation is employed for the short term, and the ratio of diluting smoke is 3.52 as great as that value for long term. The complementary ventilation employed for short time may get an improvement in energy efficiency.

The data in Table 3 show that the design air volume in the uphill tunnel is determined by dilution smoke, while that in downhill tunnel is determined by the minimum air exchange, both the short term and the long term, when the ventilation system was designed with the longitudinal ventilation. In the design, the total required air volume is $663.32 \mathrm{~m}^{3} / \mathrm{s}$ of the short term, and $979.39 \mathrm{~m}^{3} / \mathrm{s}$ of the long term. However, the design air volume is determined by minimum air exchange in redesign with the complementary ventilation, in which the total required air volume for short term is $597.55 \mathrm{~m}^{3} / \mathrm{s}$, with a decrease rate of $9.92 \%$, and $796.74 \mathrm{~m}^{3} / \mathrm{s}$ with a decrease rate of $18.6 \%$, for the long term. The smoke control U/D value is 3.52 , which makes the sum air demand of diluting smoke (484.52 $\mathrm{m}^{3} / \mathrm{s}$ and $\left.767.92 \mathrm{~m}^{3} / \mathrm{s}\right)$ is lower than that of the minimum exchange $\left(597.55 \mathrm{~m}^{3} / \mathrm{s}\right.$ and $\left.796.74 \mathrm{~m}^{3} / \mathrm{s}\right)$. Compared with the 


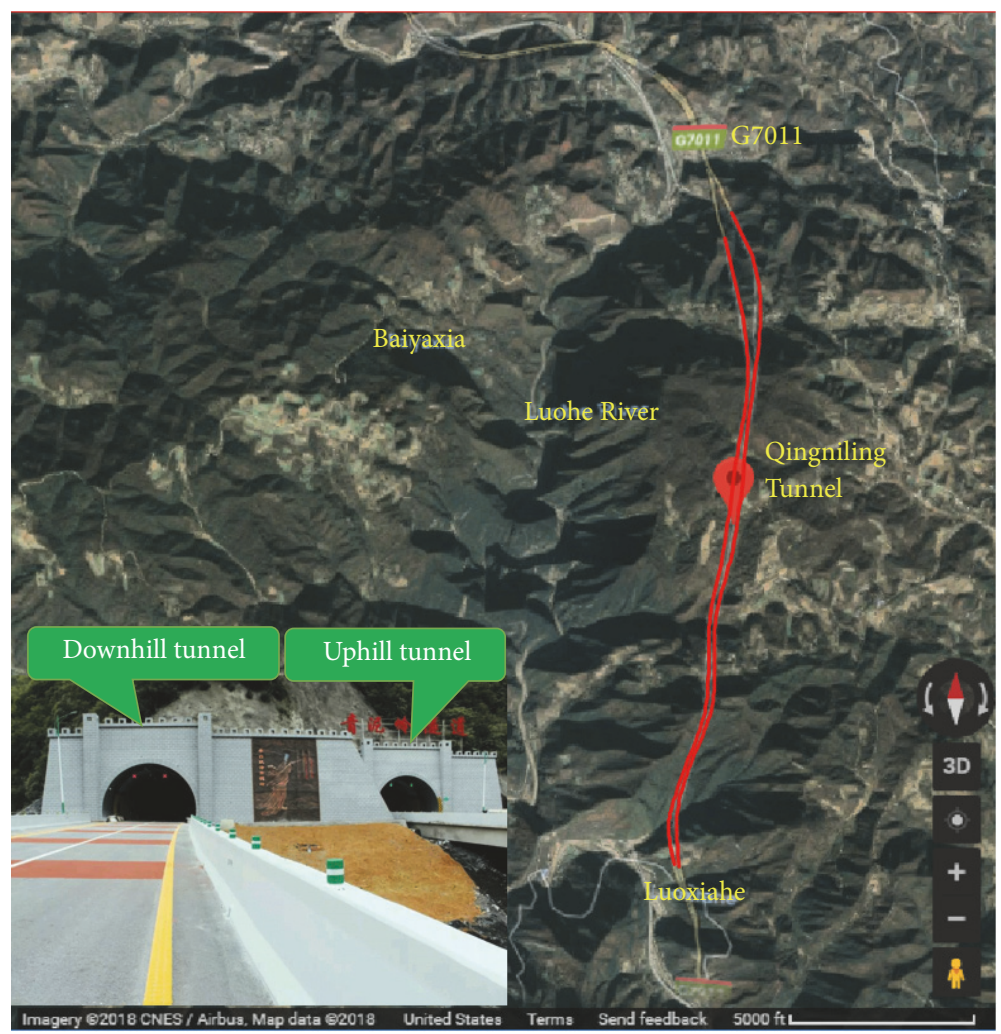

Figure 4: Qingniling Tunnel.

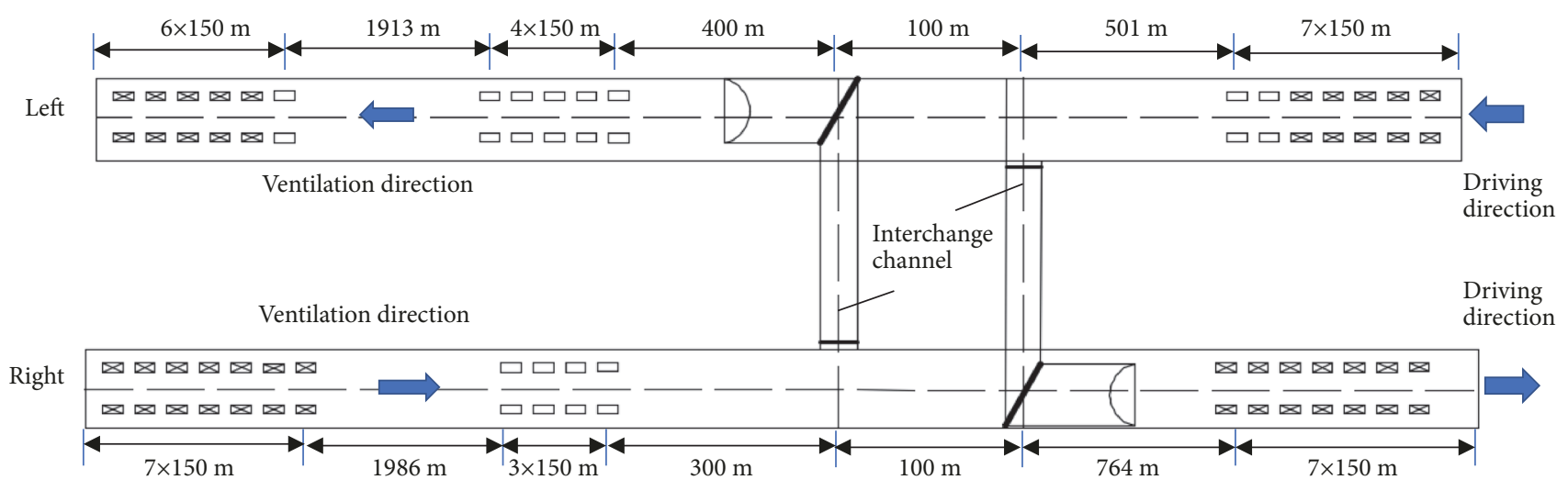

$凶$ Jet fan for short term

$\square$ Jet fan for long term

FIgURE 5: Original ventilation system design for the Qingniling Tunnel.

design air volume of original complementary scheme, the reduction of design air volume is $121.39 \mathrm{~m}^{3} / \mathrm{s}$, and the decrease rate is still $10.4 \%$.

4.2. Redesign for Short Term. The short-term ventilation system was redesigned with complementary ventilation system by using the optimization method, and the normal complementary mode was adopted. Then, the constraints of $Q_{7}=0, P_{\mathrm{F} 7}=0$ were added, and the optimal single U-type scheme for energy saving was worked out. These schemes were compared to the original design in terms of the energy consumption, and ventilation effects, as shown in Table 4.

The data in Table 4 show that the complementary ventilation scheme is more efficient than the longitudinal ventilation scheme, and the normal complementary mode is more efficient than the single U-type mode. As the total required thrust decreases from 222.38 Pa to $129.15 \mathrm{~Pa}$, the gross power of the normal complementary mode decreases from $600 \mathrm{~kW}$ to $360 \mathrm{~kW}$, which is a decrease of $240 \mathrm{~kW}$, corresponding to a 
TABLE 3: Required air volumes $\left(\mathrm{m}^{3} / \mathrm{s}\right)$.

\begin{tabular}{|c|c|c|c|c|c|c|c|c|c|}
\hline \multirow{2}{*}{\multicolumn{2}{|c|}{ Design conditions }} & \multicolumn{4}{|c|}{ Short term (2025) } & \multicolumn{4}{|c|}{ Long term (2033) } \\
\hline & & Uphill & Downhill & Sum & $\mathrm{U} / \mathrm{D}$ & Uphill & Downhill & Sum & $\mathrm{U} / \mathrm{D}$ \\
\hline \multirow{2}{*}{ Pollutants dilution } & $\mathrm{CO}$ & 181.47 & 176.05 & 357.52 & 1.03 & 300.10 & 291.13 & 591.23 & 1.03 \\
\hline & Smoke & $377.42 *$ & 107.1 & 484.52 & 3.52 & $598.18 *$ & 169.74 & 767.92 & 3.52 \\
\hline \multicolumn{2}{|c|}{ Fire emergency } & 188.37 & 188.37 & 376.74 & 1 & 188.37 & 188.37 & 376.74 & 1 \\
\hline \multicolumn{2}{|c|}{ Minimum air exchange } & 311.65 & $285.9 *$ & $597.55 *$ & 1.09 & 415.53 & $381.21 *$ & $796.74 *$ & 1.09 \\
\hline \multicolumn{2}{|c|}{ Maximum value } & 377.42 & 285.9 & 663.32 & 1.32 & 598.18 & 381.21 & 979.39 & 1.57 \\
\hline
\end{tabular}

Note: the item marked with $*$ indicates the maximum required air volume for tunnels; "U/D" indicates the required air flow ratio of the uphill and downhill tunnel.

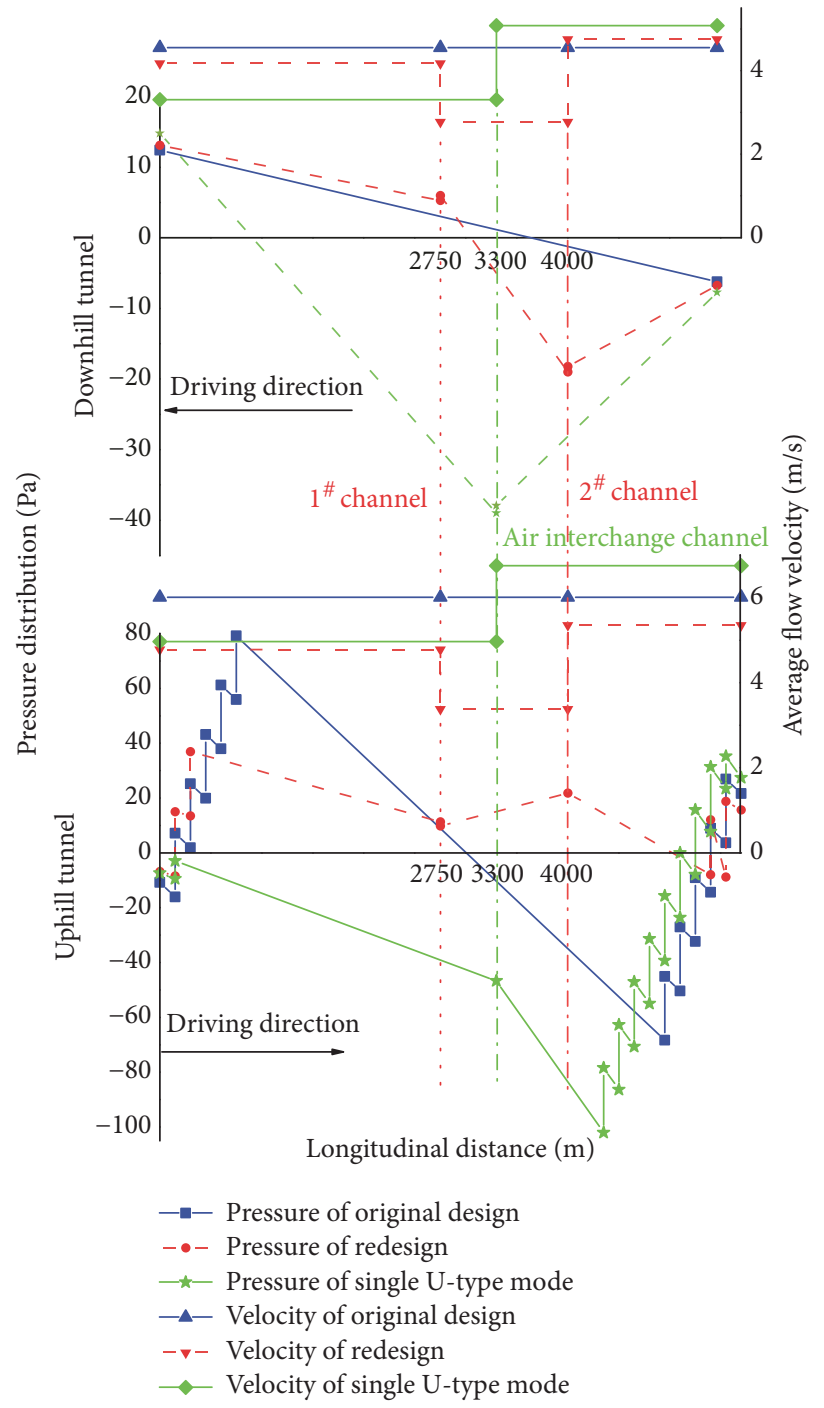

FIGURE 6: Comparation of pressure and flow velocity distribution in tunnels.

realised energy conservation of $40 \%$. Assuming the working time of the fans is $10 \mathrm{~h} / \mathrm{d}$, and the annual energy consumption cost can be reduced by 146 thousand dollars on average, which demonstrates great economic and ecological benefits. While the energy saving of the optimal single U-type scheme is only $60 \mathrm{~kW}$, it is equal to $25 \%$ of the normal complementary mode. The total air volume and the required thrust also increase to $631 \mathrm{~m}^{3} / \mathrm{s}$ and $207.08 \mathrm{~Pa}$, respectively.

The pressure and velocity profile of different schemes are shown in Figure 6. In original design, longitudinal ventilation is adopted, and 10 jet fans are installed in the inlet and outlet section of the uphill tunnel, while the number of the 


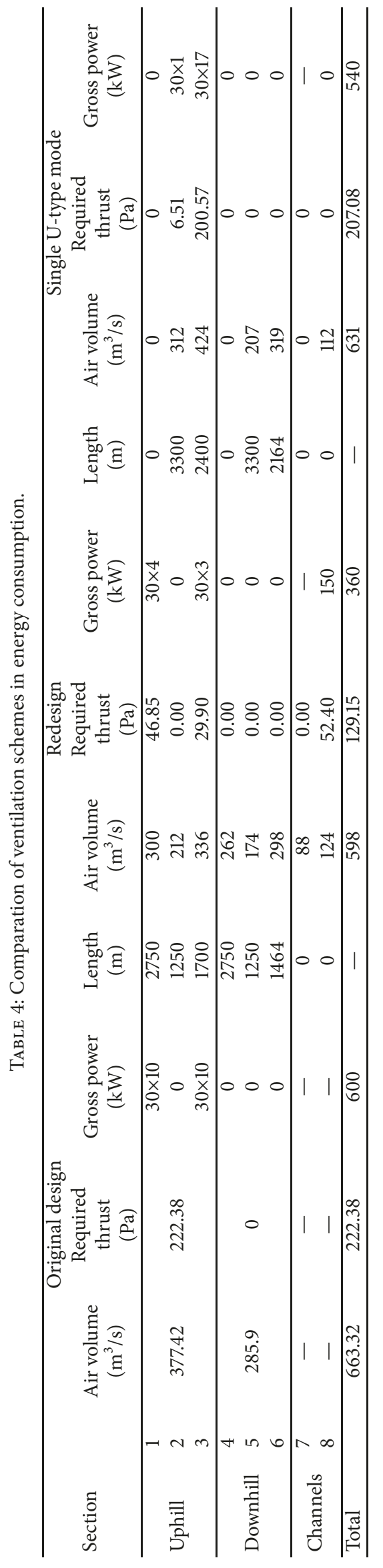



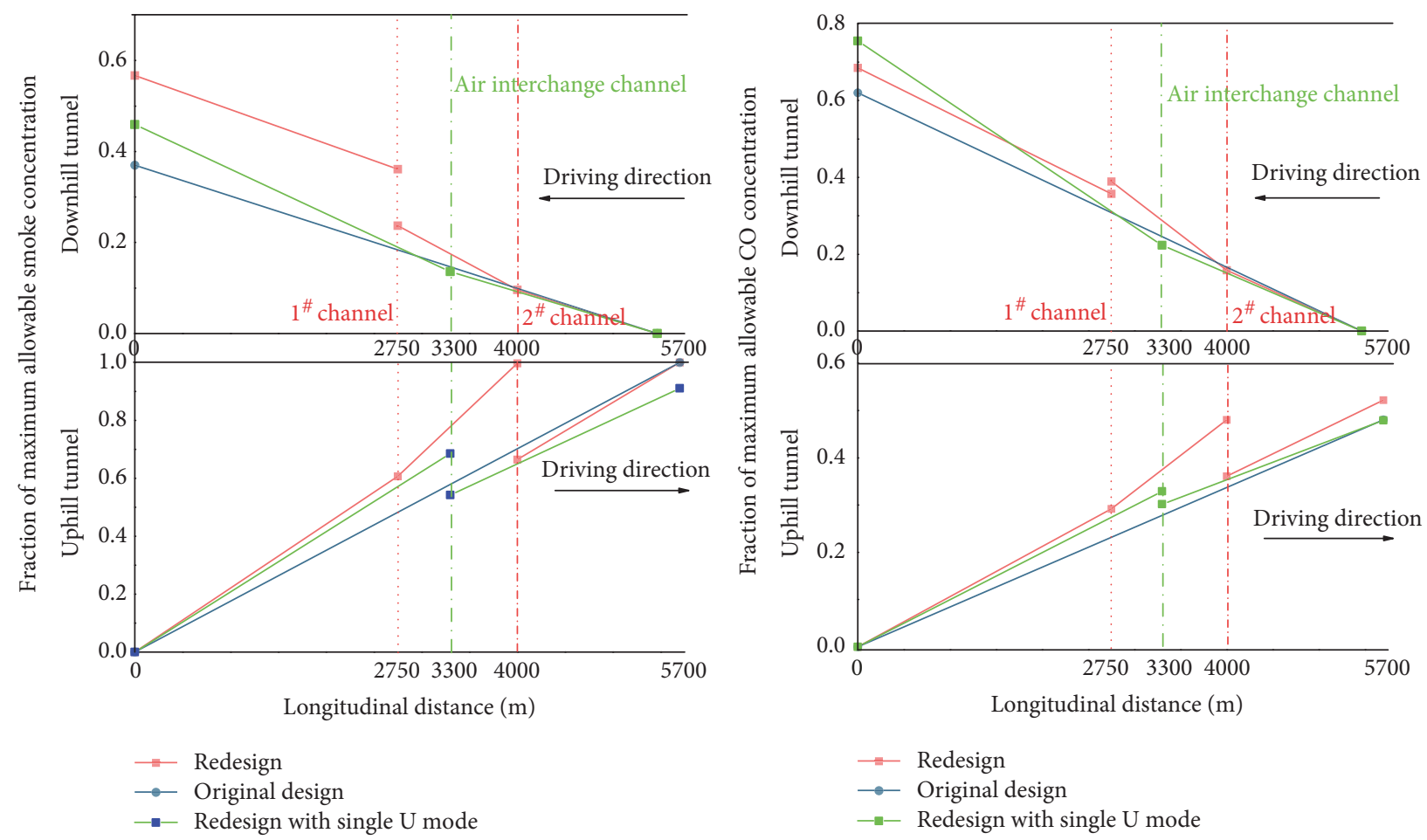

FIGURE 7: Comparation of short-term pollutants concentration distribution in tunnels.

downhill tunnel is 0 , and the traffic force and nature wind pressure provided the thrust. In the redesign, there are 4 jet fans installed in the inlet section and 3 jet fans in the outlet section of the uphill tunnel for the decrease of ventilation resistance resulting from the air volume decreasing. Fans are also installed in the second air interchange channel to induce the air from the inlet of downhill tunnel into the outlet section of uphill tunnel through the channel. While no fan is installed in the first channel, the air flow in that is induced by the pressure difference between the inlet and outlet of the channel. In single U-type mode scheme, most fans of the uphill tunnel are installed in the outlet section, and the air is induced from the uphill and downhill tunnels. The traffic force provides the most thrust in other sections. Additionally, the flow in the interchange channel is induced by the pressure difference between the inlet and outlet of it.

Figure 7 shows the pollutants concentrations (smoke and $\mathrm{CO})$ profile of different schemes. The figures show that the smoke and CO concentrations in the uphill tunnel of the redesign scheme increase faster than that of original scheme, and the difference between the two schemes reaches the maximum at the second air interchange channel. Then the difference between two schemes keeps steady, after a sudden decrease at the second air interchange channel. While in the downhill tunnel, the smoke and CO concentrations of the redesign are a little lower than those of the original design at the inlet section. Then the concentrations of the redesign increase fast and surpass the original design in the middle section. At the outlet section, the difference between the two schemes keeps steady, after a sudden change at the second air interchange channel.
Because the design air volume of single U-type mode is greater than that of the normal complementary mode, the smoke and CO concentrations with normal complementary mode are higher than those of the single U-type mode, except for the CO concentration in the outlet section of downhill tunnel.

Additionally, only the maximum smoke concentration of the uphill tunnel reaches the maximum allowable value in the original design and redesign, and the maximum smoke concentration of the downhill tunnel and the maximum CO concentration of twin tunnels are far below the maximum allowable value. However, the concentration of redesign is higher than that of the original design at the most range of length, which means that fresh air is utilised more efficiently in the redesign complementary ventilation.

4.3. Redesign for Long Term. The long-term ventilation system was redesigned with normal complementary ventilation mode, and the scheme was compared to that designed with original design in terms of the ventilation effects, and energy consumption.

The data in Table 5 show that the redesign scheme is significantly different from the original scheme. The location of the first air interchange channel moves from $3700 \mathrm{~m}$ to $3650 \mathrm{~m}$ away from the uphill inlet. The design air volumes of twin tunnels are not equal, and the air volumes of two air interchange channels are also not equal. The data also reveal that the redesign scheme is more efficient than the original scheme. While the total required thrust decreases from $920.1 \mathrm{~Pa}$ to $568 \mathrm{~Pa}$, the gross power decreases from 2790 


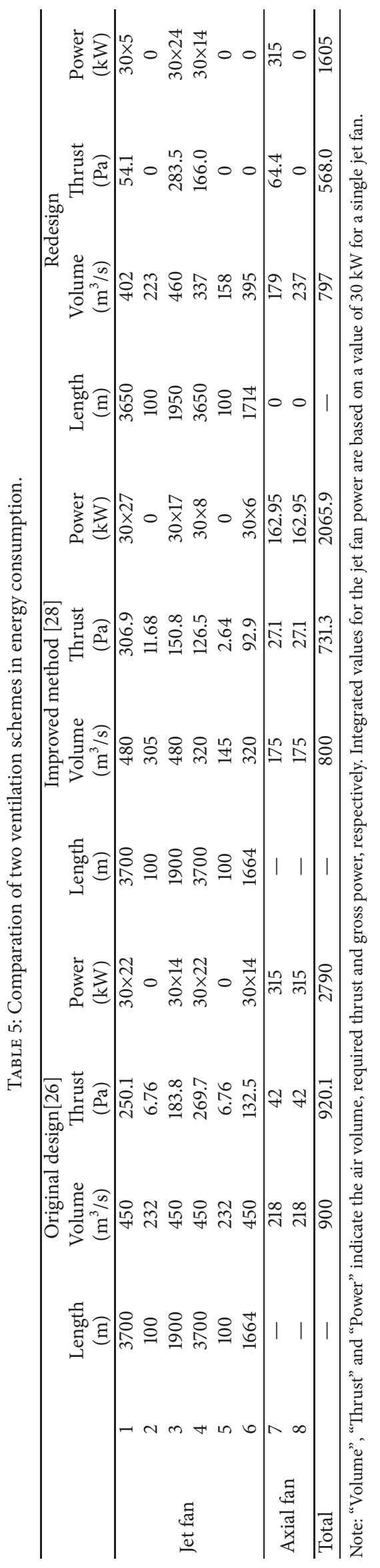



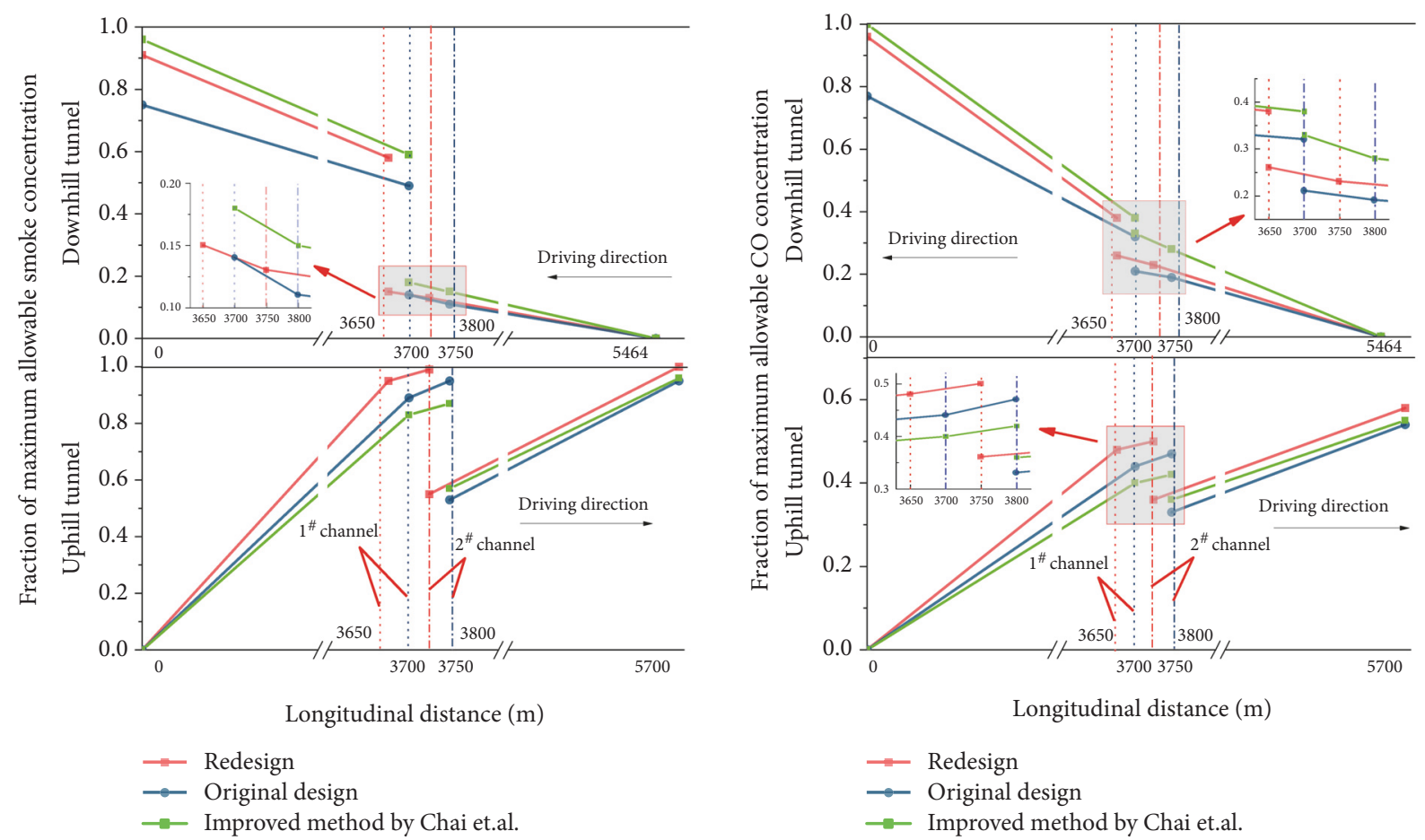

FIgURE 8: Comparation of long-term pollutant concentration distribution in tunnels.

$\mathrm{kW}$ to $1605 \mathrm{~kW}$, which is a decrease of $1185 \mathrm{~kW}$, corresponding to a realised energy conservation of $42.5 \%$. Assuming the working time of the fans is $10 \mathrm{~h} / \mathrm{d}$, the annual energy consumption cost can be reduced by 720.9 thousand dollars on average. Even compared with the improved method proposed by Chai et al., the gross power is $2065.9 \mathrm{~kW}$, the decrease is still $460.9 \mathrm{~kW}$, and the energy conservation is 22.3\%; therefore, 280.4 thousand dollars energy cost can be saved. Great economic and ecological benefits can be obtained.

Figure 8 shows the pollutants concentrations (smoke and $\mathrm{CO}$ ) profile of redesign complementary and original complementary ventilation for long term; the pollutants concentrations of redesign and the improved method are greater than the original method at most range, but it does not exceed the maximum allowable, which means that the fresh air is utilised more efficiently with the improved method. Because the redesign air volume of single tunnel is lower than that of the original scheme, the pollutants concentration of redesign is higher than that of the original scheme at the most range of length and increases faster, in the uphill and downhill tunnels. Compared to the improved method by Chai et al., the redesign air volume of the uphill tunnel is lower than the improved method, while that of the downhill tunnel is inverse. So, the pollutants concentration of the uphill tunnel is greater than that of the improved method at most range and increases faster, while that of the downhill tunnel is lower than that of the improved method and increases slower. And, owing to the flexible scheme for air volume, a better energy efficiency is obtained. The energy consumption of optimization method is lower than that of the improved method, as shown in Figure 9, although the total design air volumes of them are approximately equal (shown in Table 5).

The pressure and velocity profile of original and redesign schemes are shown in Figure 9. In the original design, 22 jet fans are installed in the section of uphill-tunnel inlet and downhill-tunnel outlet, 14 jet fans are installed in downhilltunnel inlet and uphill-tunnel outlet section, and 2 axial fans are installed in two air interchange channels, respectively. In the redesign scheme, owing to the flow velocity reducing in the uphill and downhill tunnels except the outlet section of uphill tunnel, most jet fans are installed in the outlet section of the uphill tunnel. 24 jet fans in the outlet section of the uphill tunnel and 14 jet fans in the outlet section of the downhill tunnel, only 5 jet fans in the inlet section of the uphill tunnel, no jet fan in the outlet section of downhill tunnel, and only 1 axial fan in the first air interchange channel to induce the air from the inlet of the uphill tunnel into the outlet section of the downhill tunnel through the channel are installed. While no fan is installed in the second channel, the air flow in that is induced by the pressure difference between the inlet and outlet of the channel.

As shown in Figure 9, the flow velocity in uphill tunnel of redesign is lower than that of the improved method by Chai et al., while that in the downhill tunnel is inversed. So, the fans installed in uphill tunnel of redesign are less than those of the improved method, while those in the downhill tunnel are also inversed. 


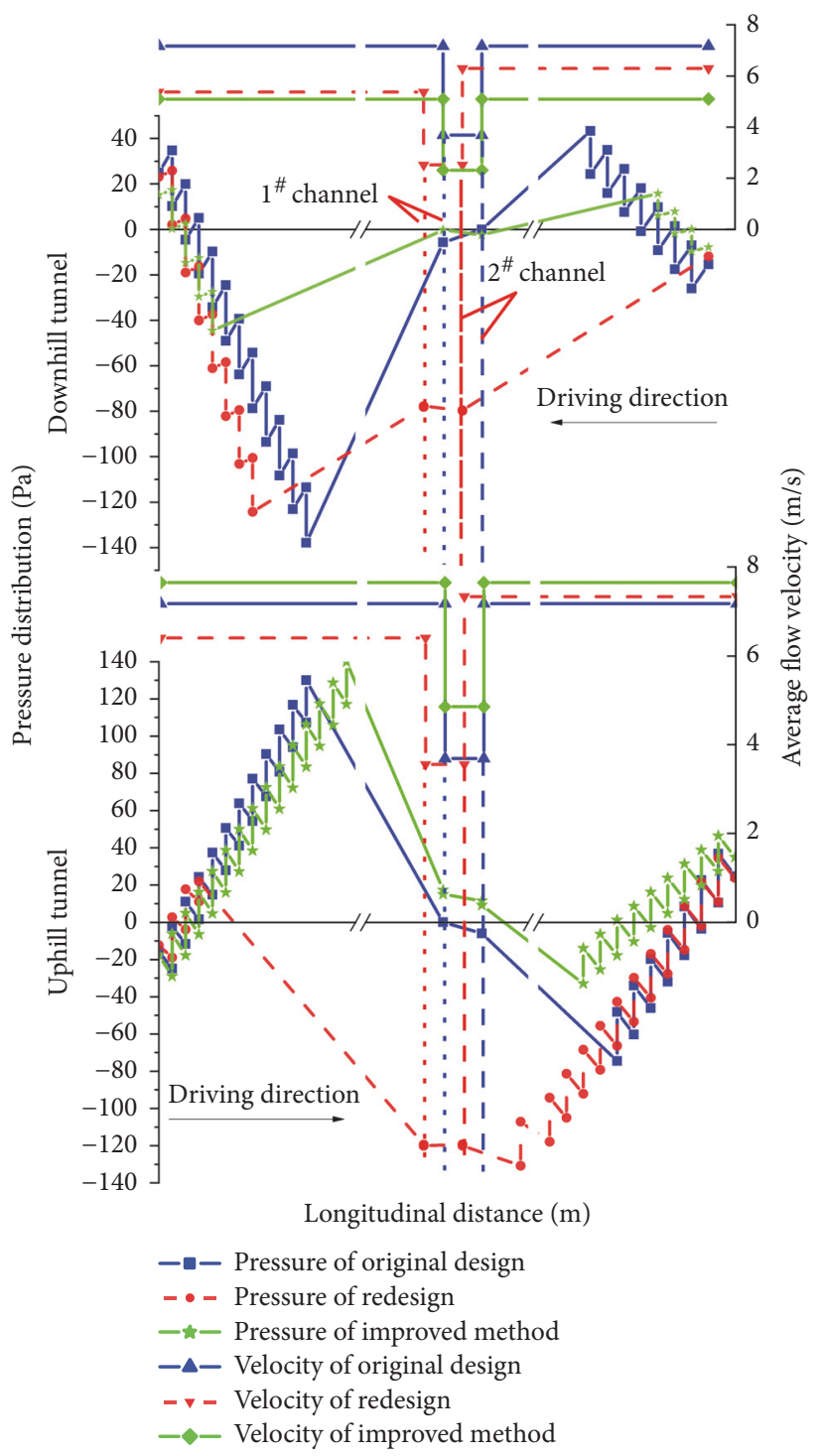

FIgURE 9: Comparation of pressure and flow velocity distribution in tunnels.

4.4. Comparison. The ventilation systems of the two additional highway tunnels, Dabieshan Tunnel (shown in Figure 10) and Lianghekou Tunnel (shown in Figure 11), were redesigned, and the normal complementary mode was adopted in these tunnels. The energy savings achieved in these tunnels are listed in Table 6. With a decrease in the total design volume and interchange volume, the energy cost is significantly reduced, and the annual cost of ventilation operation is decreased by hundreds of thousands of dollars.

In longitudinal ventilation remoulding, the air interchange channel of Dabieshan Tunnel is $4100 \mathrm{~m}$ away from the uphill-tunnel, and the distance of Lianghekou Tunnel is 2650 $\mathrm{m}$. Even though the reduction of total design air volume is very little, in fact the total air volume of Lianghekou Tunnel increases $6 \mathrm{~m}^{3} / \mathrm{s}$, and the gross power is reduced more than $50 \%$, which is benefited from the short distance of great air volume, while the smoke concentration is not greater than the threshold value, as shown in Figure 12.
In complementary ventilation redesign, the air interchange channel location of Dabieshan Tunnel is $3400 \mathrm{~m}$, the same as the original complementary design scheme, while the location of Lianghekou Tunnel is $2300 \mathrm{~m}$ away from the uphill-tunnel inlet, $175 \mathrm{~m}$ away from the original design location. The reduction of total design air volume is $41 \mathrm{~m}^{3} / \mathrm{s}$ in Dabieshan Tunnel, the gross power is reduced $1185 \mathrm{~kW}$, the energy conservation is $58.1 \%$, and 720.88 thousand of dollars for ventilation operation is saved every year. And the smoke concentration is greater than the original design but lower than the threshold value, as shown in Figure 13(a). Even though the total design air volume of Lianghekou Tunnel is nearly equal to that of the original design, the gross power is still reduced $540 \mathrm{~kW}$, the energy conservation reaches $45 \%$, and 328.5 thousand of dollars for ventilation operation is saved every year, while the smoke concentration is similar to that of the original design and lower than the threshold value, as shown in Figure 13(b). 


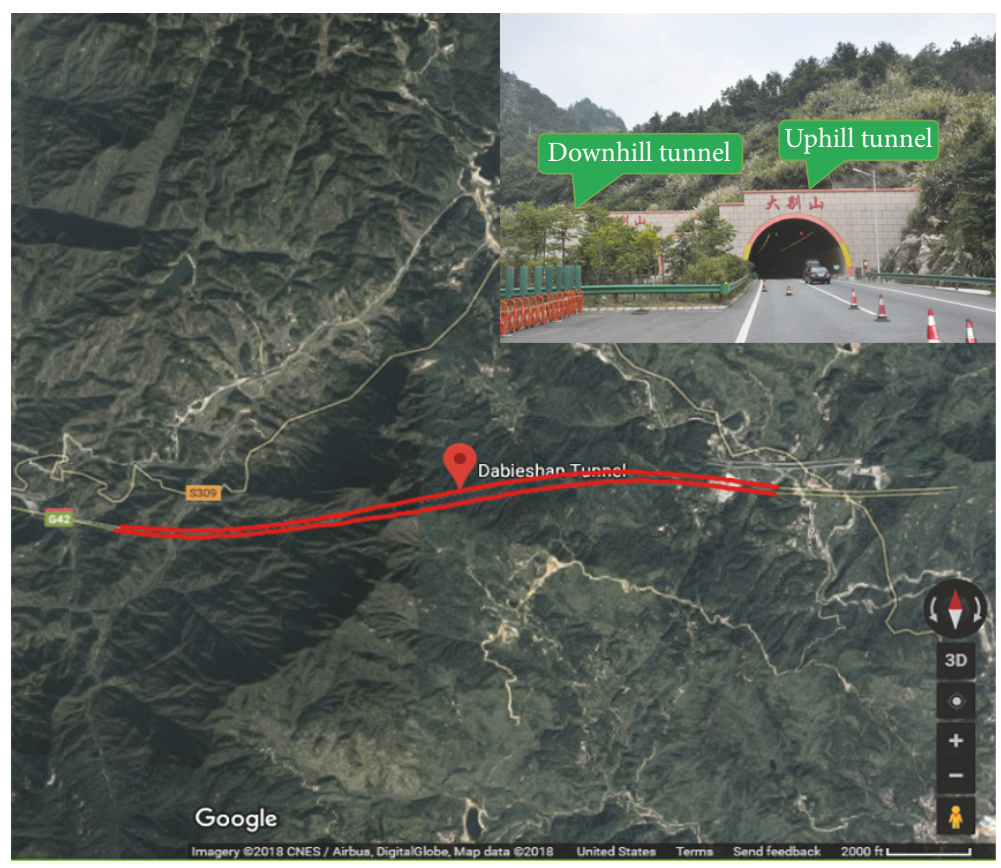

Figure 10: Dabieshan Tunnel.

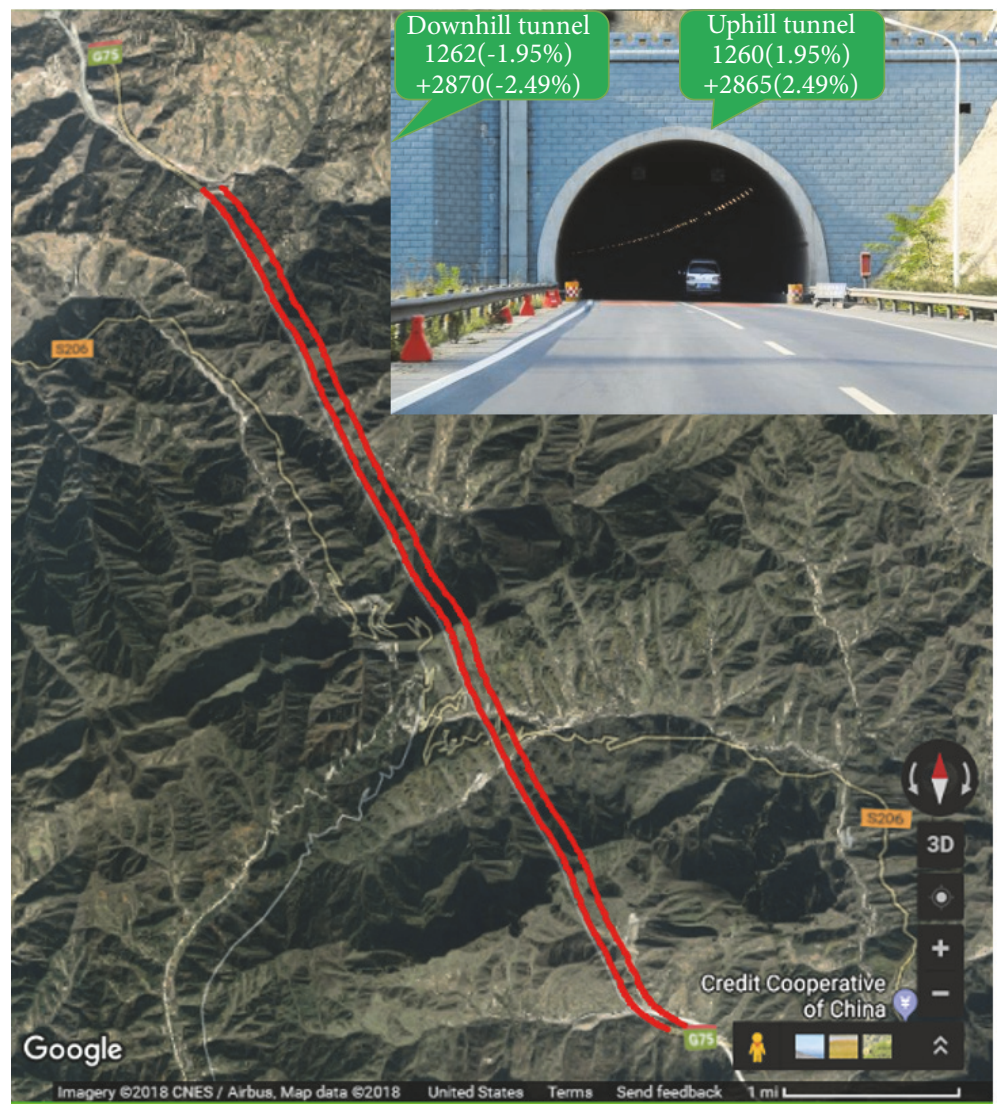

Figure 11: Lianghekou Tunnel. 


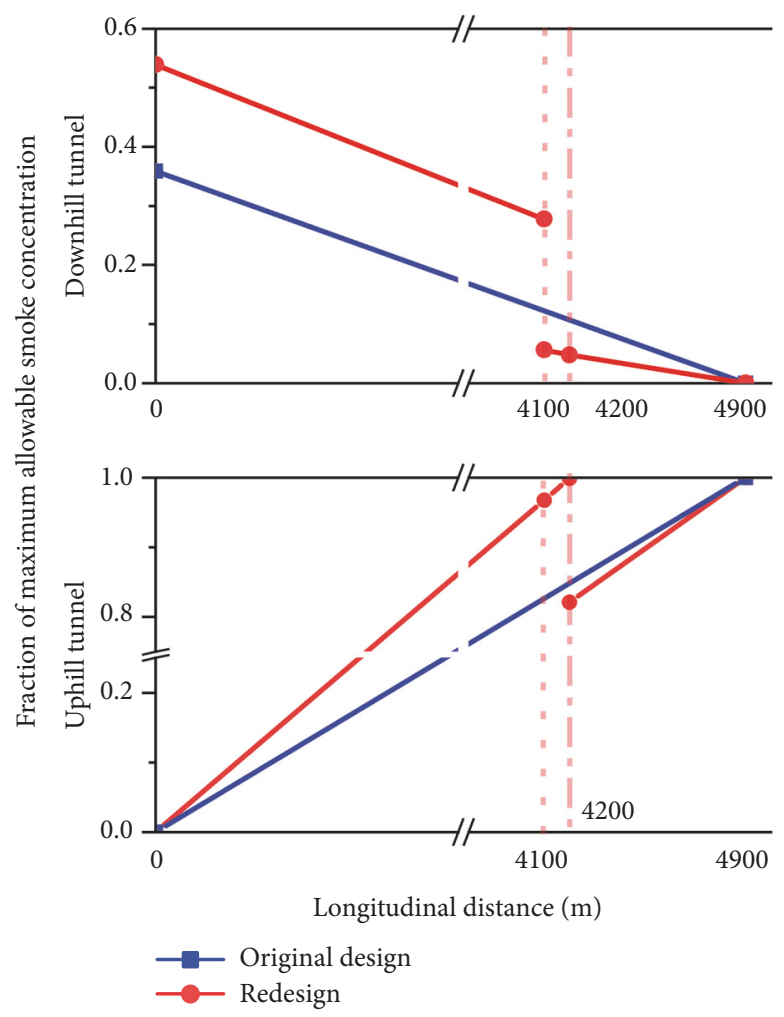

(a) Dabieshan Tunnel

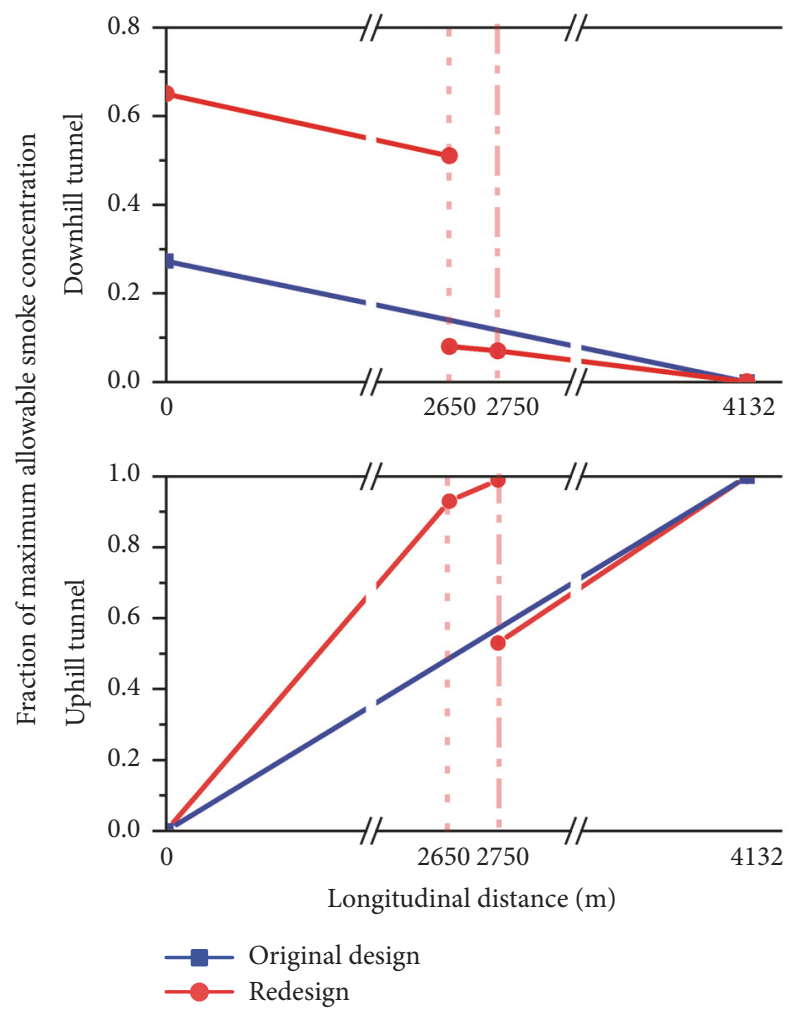

(b) Lianghekou Tunnel

FIGURE 12: Smoke concentration distribution in Dabieshan Tunnel and Lianghekou Tunnel for short term.

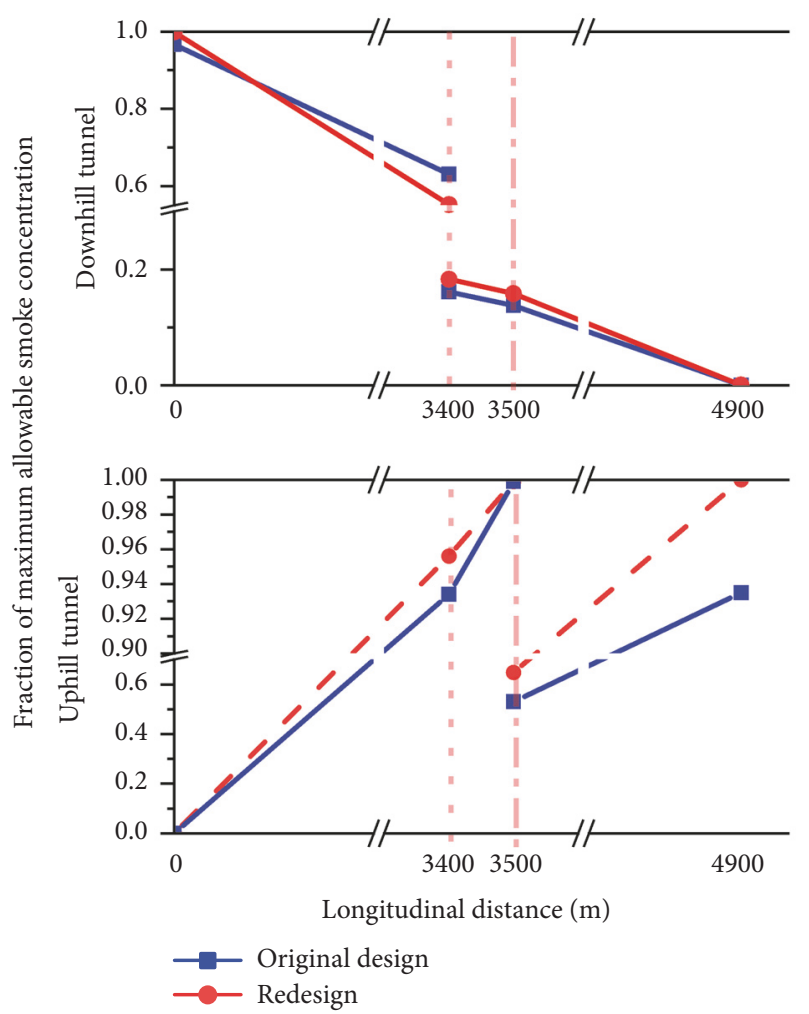

(a) Dabieshan Tunnel

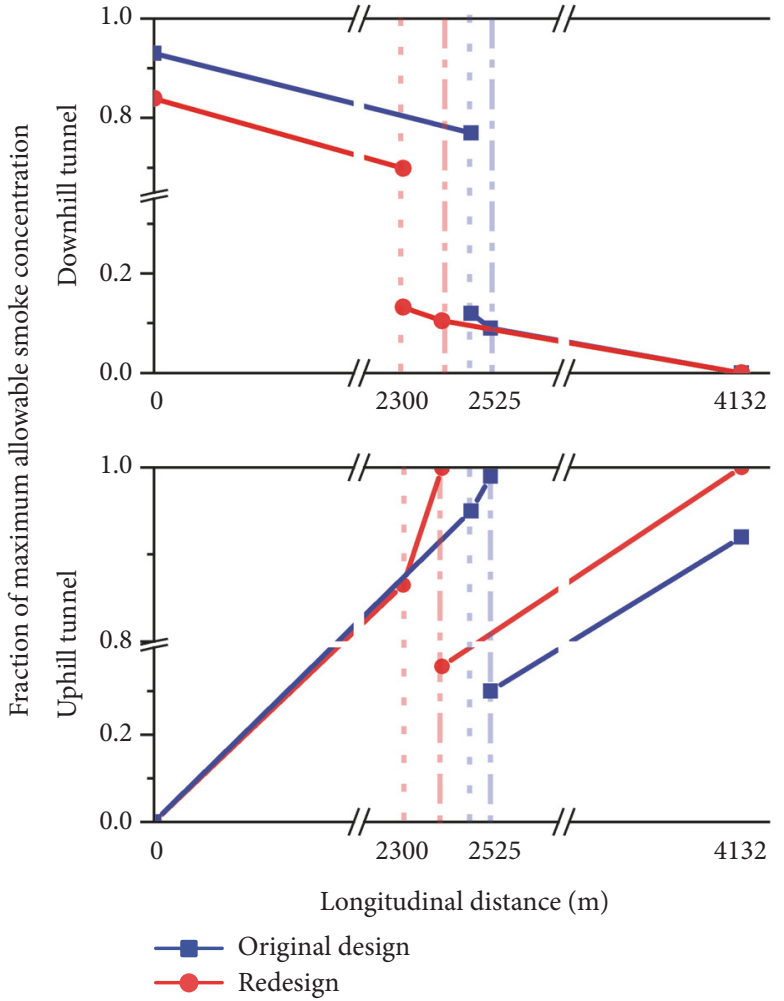

(b) Lianghekou Tunnel

FIGURE 13: Smoke concentration distribution in Dabieshan Tunnel and Lianghekou Tunnel for long term. 


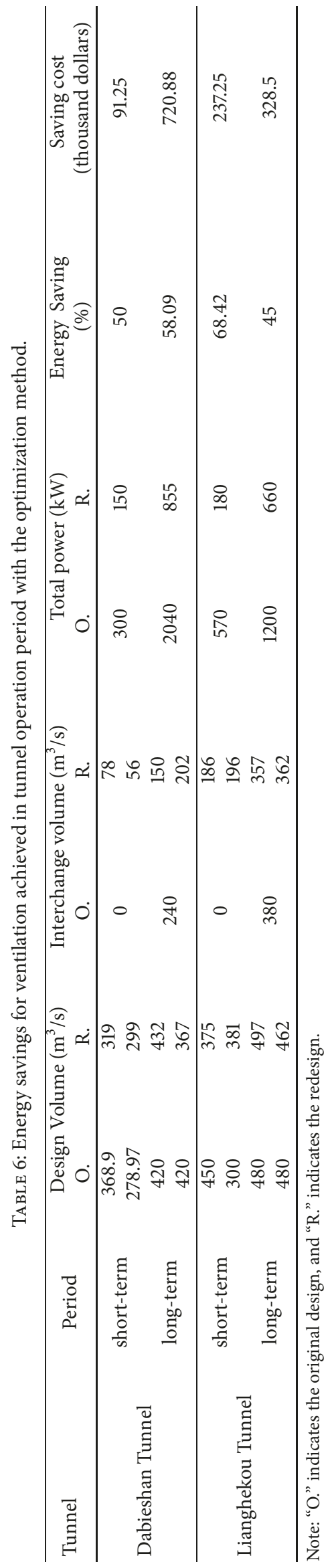




\section{Conclusion}

This paper proposed an optimization model for twin-tunnels complementary ventilation design. And the complementary ventilation system utilization in energy conservation of longitudinal ventilation remoulding was discussed. The effectiveness of the optimization method and the energy saving in longitudinal ventilation remoulding was verified by redesigning three tunnels where the original design longitudinal ventilation was adopted in the short term and the complementary ventilation was adopted in the long term, with the optimization method. The main results were drawn as follows:

(1) Optimization design method can significantly increase the energy saving of the complementary ventilation. In the redesign of long-term ventilation systems, the energy consumption is reduced by $42.5 \sim 58 \%$; therefore hundreds of thousands of dollars for ventilation operation is saved every year.

(2) Remoulding ventilation schemes, longitudinal ventilation to complementary ventilation, benefits the energy conservation greatly. In the short-term ventilation systems remoulding, the energy consumption is reduced by $40 \sim$ $68.4 \%$; therefore, hundreds of thousands of dollars for ventilation operation is saved every year.

(3) The normal mode is more effective than the single U-type mode in remolding longitudinal ventilation system for energy saving. For the air exchange between uphill and downhill tunnels is bidirectional in the normal mode; the air volume can be reduced more significantly, while that of the single U-type mode is unidirectional; the downhill tunnel provides fresh air for the uphill tunnel.

(4) It is not necessary to install fans in each air interchange channel for inducing the air into the channel, for the pressure difference between the inlet and outlet of the channel is enough.

\section{Data Availability}

The data used to support the findings of this study are included within the article.

\section{Conflicts of Interest}

The authors declare that there are no conflicts of interest regarding the publication of this article.

\section{Acknowledgments}

This research was supported by the Key Research Program of Henan Provincial Department of Transportation (2017Z4). The authors would also like to express special thanks to Phd. Junling Qiu and Xing Liang from Changan University for their assistance during the revision of works.

\section{References}

[1] C.-Y. Chung and P.-L. Chung, "A numerical and experimental study of pollutant dispersion in a traffic tunnel," Environmental Modeling \& Assessment, vol. 130, no. 1-3, pp. 289-299, 2007.
[2] S. Bari and J. Naser, "Simulation of airflow and pollution levels caused by severe traffic jam in a road tunnel," Tunnelling and Underground Space Technology, vol. 25, no. 1, pp. 70-77, 2010.

[3] P.-J. Sturm, R. Brandt, F. Hervé et al., Road Tunnels: Vehicle Emissions and Air Demand for Ventilation, 2012.

[4] A. Caserta, Aerodynamics And Ventilation of Vehicle Tunnels: Principles, Analysis and Design, John Wiley Sons, Inc, New Jersey, NJ, USA, 2000.

[5] M. Gharouni-Nik, "Design of ventilation for a highway tunnel in a very crowded urban area," in Proceedings of the 11th ACUUS International Conference - Underground Space: Expanding the Frontiers, pp. 583-588, Athens, Greece, September 2007.

[6] R. O. Carvel, A. N. Beard, and P. W. Jowitt, "The influence of longitudinal ventilation systems on fires in tunnels," Tunnelling and Underground Space Technology, vol. 16, no. 1, pp. 3-21, 2001.

[7] F. Chen, "Smoke propagation in road tunnels," Applied Mechanics Reviews, vol. 53, no. 8, pp. 1161-1179, 2000.

[8] W. K. Chow and M. Y. Chan, "Field measurement on transient carbon monoxide levels in vehicular tunnels," Building and Environment, vol. 38, no. 2, pp. 227-236, 2003.

[9] W. K. Chow, K. Y. Wong, and W. Y. Chung, "Longitudinal ventilation for smoke control in a tilted tunnel by scale modeling," Tunnelling À Underground Space Technology Incorporating Trenchless Technology Research, vol. 25, no. 2, pp. 122-128, 2010.

[10] H. Ingason and Y. Z. Li, "Model scale tunnel fire tests with longitudinal ventilation," Fire Safety Journal, vol. 45, no. 6-8, pp. 371-384, 2010.

[11] X. X. Nie, X. B. Wei, X. C. Li, and C. W. Lu, "Heat treatment and ventilation optimization in a deep mine," Advances in Civil Engineering, 2018.

[12] J. Qiu, X. Wang, J. Lai, Q. Zhang, and J. Wang, "Response characteristics and preventions for seismic subsidence of loess in Northwest China," Natural Hazards, vol. 92, no. 7, pp. 1-27, 2018.

[13] Y. Wu and M. Z. A. Bakar, "Control of smoke flow in tunnel fires using longitudinal ventilation systems-a study of the critical velocity," Fire Safety Journal, vol. 35, no. 4, pp. 363-390, 2000.

[14] Q. X. Yan, H. Chen, W. Y. Chen, J. C. Zhang, S. Q. Ma, and $\mathrm{X}$. Huang, "Dynamic characteristic and fatigue accumulative damage of a cross shield tunnel structure under vibration load," Shock and Vibration, 2018.

[15] L. Yi, J. L. Niu, Z. S. Xu, and D. X. Wu, "Experimental studies on smoke movement in a model tunnel with longitudinal ventilation," Tunnelling and Underground Space Technology incorporating Trenchless Technology Research, vol. 35, no. 3, pp. 135-141, 2013.

[16] Z. Q. Zhang, X. Q. Shi, B. Wang, and H. Y. Li, "Stability of NATM tunnel faces in soft surrounding rocks," Computers \& Geosciences, vol. 96, pp. 90-102, 2018.

[17] T. Y. Chen, Y. T. Lee, and C. C. Hsu, "Investigations of pistoneffect and jet fan-effect in model vehicle tunnels," Journal of Wind Engineering \& Industrial Aerodynamics, vol. 73, no. 2, pp. 99-110, 1998.

[18] J. Qiu, Y. Qin, J. Lai et al., "Structural Response of the Metro Tunnel under Local Dynamic Water Environment in Loess Strata," Geofluids, vol. 2019, pp. 1-16, 2019.

[19] J. Qiu, T. Yang, X. Wang, L. Wang, and G. Zhang, "Review of the flame retardancy on highway tunnel asphalt pavement," Construction and Building Materials, vol. 195, pp. 468-482, 2019.

[20] Q. Wang and H. Sun, "Traffic Structure Optimization in Historic Districts Based on Green Transportation and Sustainable 
Development Concept," Advances in Civil Engineering, vol. 2019, pp. 1-18, 2019.

[21] M. Huang and B. Y. Pan, "Research of ventilation design for highway tunnel," in Proceedings of the International Conference on Management and Service Science, pp. 1-3, Bangkok, Thailand, 2011.

[22] R. Ren, S. Xu, Z. Ren et al., "Numerical investigation of particle concentration distribution characteristics in twin-tunnel complementary ventilation system," Mathematical Problems in Engineering, vol. 2018, Article ID 1329187, 13 pages, 2018.

[23] M. Berner and J. Day, "Alternative methods for ventilating long road tunnels," Tunnels \& Tunnelling International, vol. 23, no. 10, 1991.

[24] G. Zhang and Lei, "Study on air interchange system for road tunnel longitudinal ventilation," Modern Tunneling Technology, 2011.

[25] Y. Q. Wang, H. U. Yan-Jie, M. Deng, F. Y. Xia, and Y. L. Xie, "Complementary ventilation operational test in large longitudinal slope double-hole tunnel," Journal of Traffic \& Transportation Engineering, 2014.

[26] F. Y. Xia, Y. Q. Wang, Y. L. Xie, S. O. Highway, and C. University, "Design method and test of twin-tunnel complementary ventilation for highway tunnel," Journal of Highway \& Transportation Research \& Development, 2015.

[27] F. Y. Xia, Y. L. Xie, Y. Q. Wang, H. U. Yan-Jie, S. O. Highway, and C. University, "Complementary ventilation modes of extralong highway tunnel," Journal of Traffic \& Transportation Engineering, 2014.

[28] L. Chai, X. Wang, X. Han et al., "Complementary ventilation design method for a highway twin-tunnel based on the compensation concept," Mathematical Problems in Engineering, vol. 2018, 13 pages, 2018.

[29] J. X. Lai, X. L. Wang, J. L. Qiu et al., "A state-of-the-art review of sustainable energy based freeze proof technology for coldregion tunnels in China," Renewable \& Sustainable Energy Reviews, vol. 82, pp. 3554-3569, 2018.

[30] Ministry of Transport of China, Guidelines for Design of Ventilation of Highway Tunnels, China Communication Press, Beijing, 2014. 


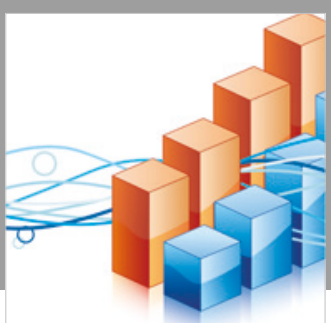

Advances in

Operations Research

\section{-n-m}
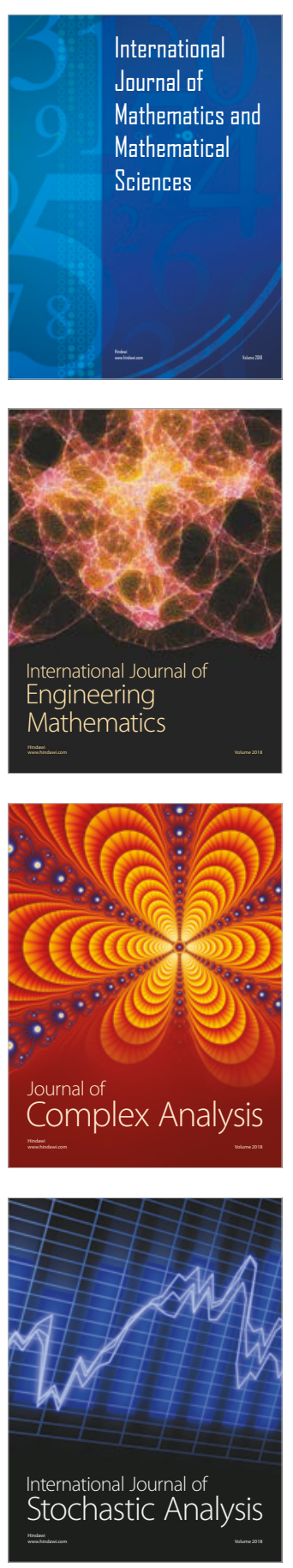
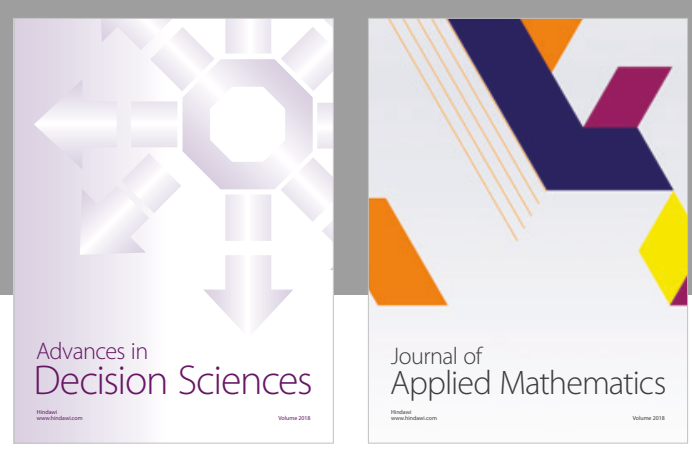

Journal of

Applied Mathematics
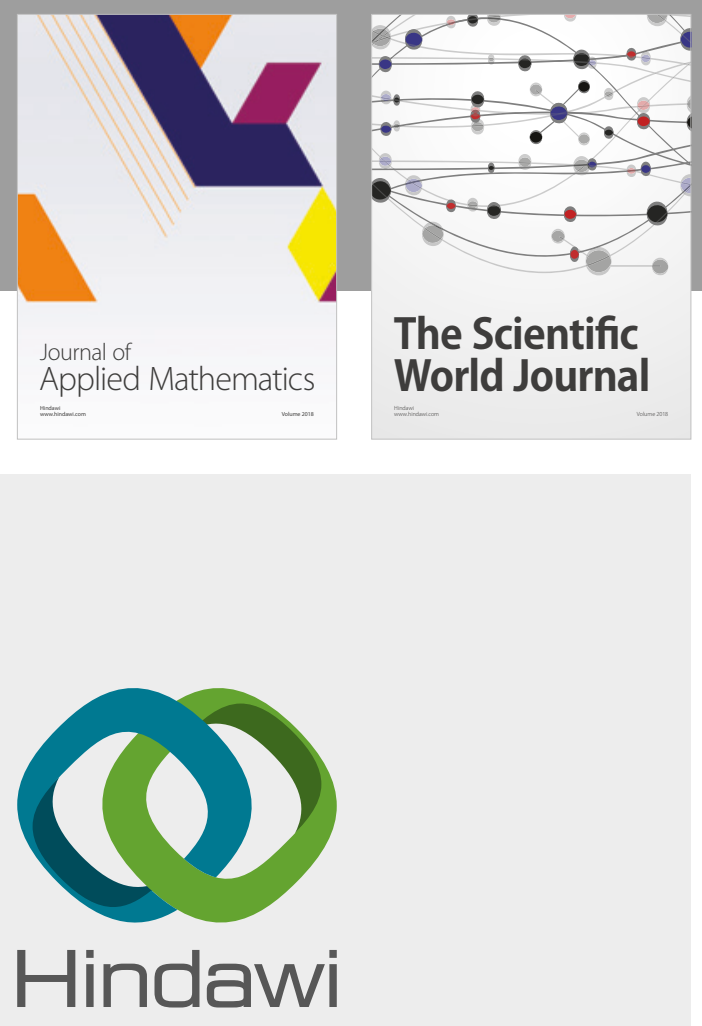

Submit your manuscripts at

www.hindawi.com

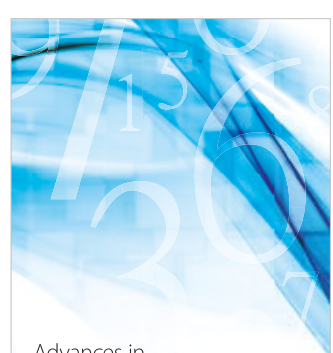

Advances in
Numerical Analysis
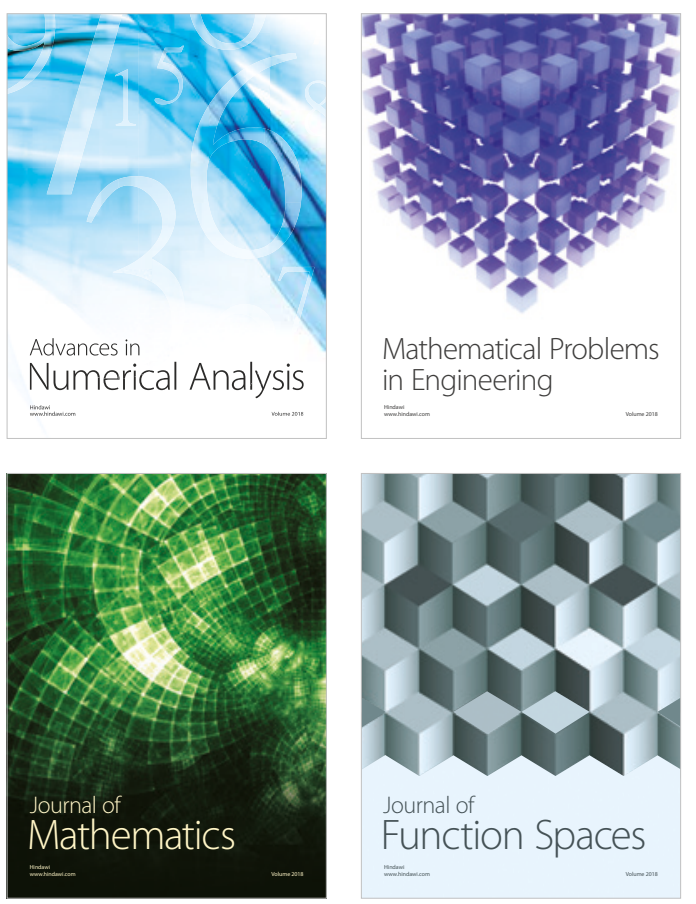

Mathematical Problems in Engineering

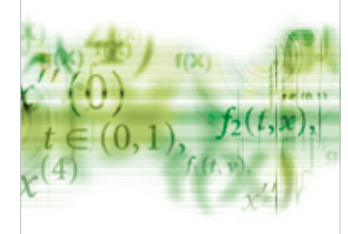

International Journal of

Differential Equations

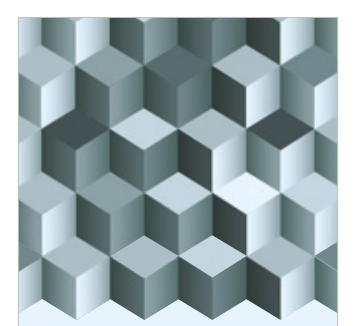

Journal of

Function Spaces

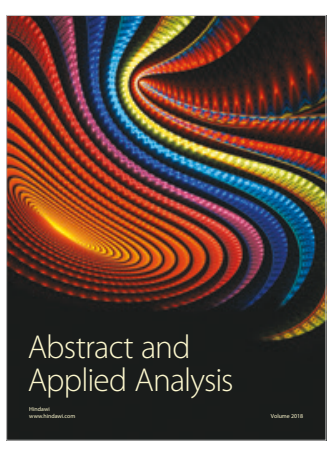

The Scientific

World Journal

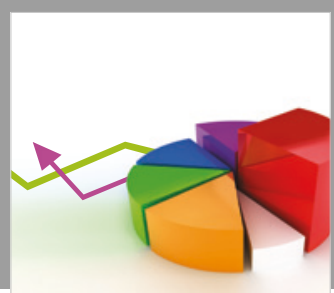

Journal of

Probability and Statistics
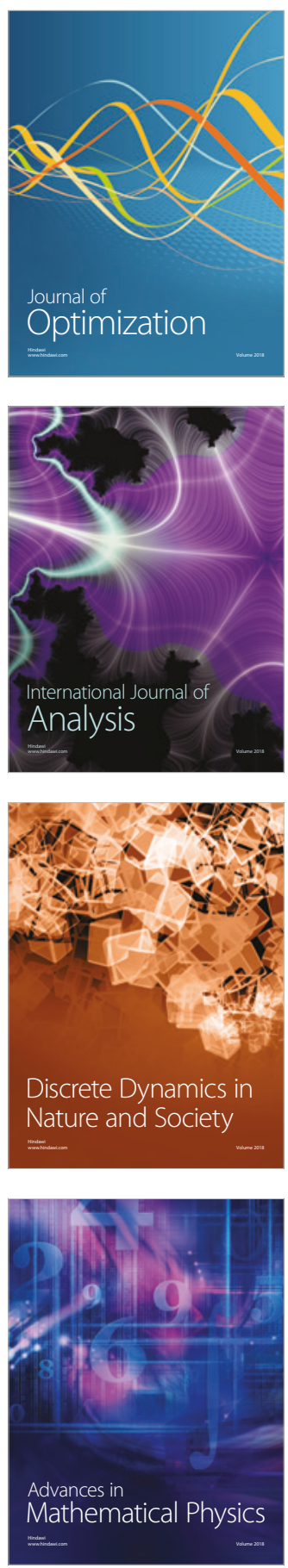